\title{
3, 3'5 Triiodo L Thyronine Induces Apoptosis in Human Breast Cancer MCF-7cells, Repressing SMP30 Expression through Negative Thyroid Response Elements
}

\author{
Pranati Sar ${ }^{1}$, Rosalima Peter ${ }^{1}$, Bandita Rath ${ }^{1}$, Alok Das Mohapatra ${ }^{2}$, Sandip K. Mishra ${ }^{1 *}$ \\ 1 Cancer Biology Lab, Department of Gene Function and Regulation, Institute of Life Sciences, Chandrasekharpur, Bhubaneswar, India, 2 Vector Born Disease Lab,
} Department of Infectious Disease Biology, Institute of Life Sciences, Chandrasekharpur, Bhubaneswar, India

\begin{abstract}
Background: Thyroid hormones regulate cell proliferation, differentiation as well as apoptosis. However molecular mechanism underlying apoptosis as a result of thyroid hormone signaling is poorly understood. The antiapoptotic role of Senescence Marker Protein-30 (SMP30) has been characterized in response to varieties of stimuli as well as in knock out model. Our earlier data suggest that thyroid hormone 3, 3'5 Triiodo L Thyronine $\left(T_{3}\right)$, represses SMP30 in rat liver.

Methodology/Principal Findings: In highly metastatic MCF-7, human breast cancer cell line T3 treatment repressed SMP30 expression leading to enhanced apoptosis. Analysis by flow cytometry and other techniques revealed that overexpression and silencing of SMP30 in MCF-7 resulted in decelerated and accelerated apoptosis respectively. In order to identify the cisacting elements involved in this regulation, we have analyzed hormone responsiveness of transiently transfected hSMP30 promoter deletion reporter vectors in MCF-7 cells. As opposed to the expected epigenetic outcome, thyroid hormone down regulated hSMP30 promoter activity despite enhanced recruitment of acetylated H3 on thyroid response elements (TREs). From the stand point of established epigenetic concept we have categorised these two TREs as negative response elements. Our attempt of siRNA mediated silencing of TR $\beta$, reduced the fold of repression of SMP30 gene expression. In presence of thyroid hormone, Trichostatin- A (TSA), which is a Histone deacetylase (HDAC) inhibitor further inhibited SMP30 promoter activity. The above findings are in support of categorisation of both the thyroid response element as negative response elements as usually TSA should have reversed the repressions.

Conclusion: This is the first report of novel mechanistic insights into the remarkable downregulation of SMP30 gene expression by thyroid hormone which in turn induces apoptosis in MCF-7 human breast cancer cells. We believe that our study represents a good ground for future effort to develop new therapeutic approaches to challenge the progression of breast cancer.
\end{abstract}

Citation: Sar P, Peter R, Rath B, Mohapatra AD, Mishra SK (2011) 3, 3'5 Triiodo L Thyronine Induces Apoptosis in Human Breast Cancer MCF-7cells, Repressing SMP30 Expression through Negative Thyroid Response Elements. PLoS ONE 6(6): e20861. doi:10.1371/journal.pone.0020861

Editor: Nai Sum Wong, University of Hong Kong, Hong Kong

Received October 4, 2010; Accepted May 14, 2011; Published June 7, 2011

Copyright: () 2011 Sar et al. This is an open-access article distributed under the terms of the Creative Commons Attribution License, which permits unrestricted use, distribution, and reproduction in any medium, provided the original author and source are credited.

Funding: This study was supported by funds from the Department of Biotechnology, Goverment of India. PS is supported by a research fellowship from University Grant Commission, Goverment of India, New Delhi. The funders had no role in study design, data collection and analysis, decision to publish, or preparation of the manuscript.

Competing Interests: The authors have declared that no competing interests exist.

*E-mail: sandipkmishra@hotmail.com

\section{Introduction}

The incidence of breast cancer has shown an alarming increase trend in recent years [1]. An estimated 1.7 million women will be diagnosed with breast cancer in 2020 which is a $26 \%$ increase from the current levels, mostly in the developing world [2,3]. The development and growth of many human cancers including breast cancers are known to be influenced by steroid hormones $[4,5]$. Abnormal responsiveness of the cells especially to estrogen hormone has been a major cause of breast cancer development and progression [6,7]. Therefore better understanding and manipulation of the endocrine milieu may provide effective palliative treatment for patients with hormone-dependent cancers $[8,9,10]$. Numerous environmental risk factors, pathological conditions and physiological agents as well as thyroid hormones have been proposed to influence the development of breast cancer [11].
Interestingly, Martinez et al reported that the addition of thyroid hormones at non physiological concentrations can alter mammary epithelial cells proliferation [12].

The thyroid gland releases two potent hormones, triiodothyronine (T3) and thyroxine (T4), which can influence and alter the basal metabolism or the oxygen consumption in virtually every cell in the body. However, due to conflicting results regarding the clinical correlation between breast cancer and thyroid diseases, any precise association between thyroid status and the pathogenesis of human breast cancer remains elusive [13]. Similar pathways are shared between thyroid hormone and estrogen in regulating proliferation and growth in the target cells, including cancer cells. So the aberrant signaling by these hormones needs to be evaluated in terms of regulated growth or cancer of the target cells. Receptors of these hormones are critically important in the above process of evaluation. Although the secretion of T4 from thyroid is 
several times greater than T3, the later is roughly two to three times more effective than the former. T3 binds to specific high affinity receptors called thyroid receptors (TRs) which belong to the super family of nuclear receptors [14] and mediate multiple effects on the phenotype, proliferation and gene expression of cultured normal mammary epithelial cells $[15,16,17]$.

The TRs are ligand modulated transcription factors encoded by two genes, TR $\alpha$ and TR $\beta$, located on human chromosomes 17 and 3 respectively [11]. Dependency of human mammary neoplasia on thyroid hormones and controversial reports in literature about the relationship between the thyroid status of the patient and neoplastic illness $[18,19,20]$ have suggested that thyroid hormone receptors (TRs) could potentially become a marker and a therapeutic target like the estrogen and progesterone receptors [21]. One of the recent studies reports substantial changes in the expression profile of TRs in breast cancer cells, suggesting a possible deregulation of TRs which could trigger breast cancer development $[21,22,23]$. However, only a few reports have described the presence of TRs in breast tumors [24,25] and breast cancer cell lines $[26,27]$. MCF-7 is one of the well defined breast cancer cell lines where presence of receptors for thyroid hormone has been well documented [26]. This finding makes it a suitable model to study the effect of thyroid hormones in breast cancer.

The effect of thyroid hormone at the cellular level is mediated through TRs, by interacting with thyroid hormone response elements (TREs) in the promoters of the target genes to regulate transcription. Depending on their ability to bind to thyroid hormone, TRs can activate or suppress gene expression in a tissue specific manner through heterodimerisation with retinoid $\mathrm{X}$ receptors (RXRs) and interaction with the positive or negative response elements commonly known as TREs in the regulatory regions of target genes [28]. The molecular mechanism of positive transcriptional regulation by TRs is well established. However, the molecular mechanism of negative regulation by nuclear receptors is poorly understood. Several hypotheses have been proposed to explain the action of TR on negative TREs [29]. One hypothesis is that the TR directly regulates transcription through direct binding to target promoter, either to unusual DNA response elements or via protein-protein interactions with other transcription factors associated with cognate response elements. Another hypothesis suggests that the role of TR is indirect mediated through the squelching of coregulators from other transcription factors. Silencing mediator for retinoic and thyroid hormone receptor (SMRT) and nuclear corepressor (NCoR) can increase basal transcription of some target genes in absence of ligand [30]. Coactivator also can play an apparently paradoxical role in T3 dependent negative regulation of some target genes [31]. On the other hand HDACs are recruited by TRs during ligand dependent negative regulation in other cases [32]. Thus, cofactor associated changes in histone acetylation, and alterations in chromatin structure, may be involved in T3 mediated negative regulation. Of note, not all negatively regulated target genes are activated in absence of ligand, suggesting that cofactors may be differentially recruited to promoters of negatively regulated target genes [33]. However there is no consensus over exact mechanism of negative regulation by TRs so far. The response elements may be defined as a negative response element if despite having the basic attribute of an open chromatin conformation such as increased recruitment of acetylated histone recruitment; the outcome is the repression of the corresponding gene.

The role of thyroid hormones in inducing apoptosis in different systems has been well documented in literature [34, 35 and 36]. SMP30 was initially identified as a novel protein that is highly expressed in hepatocytes and in renal tubular epithelia, and its amount decreases with aging [37]. The anti-apoptotic role of SMP30 has been well documented in several reported investigations [38-41]. Thus thyroid hormones and SMP30 seem to influence the process of apoptosis in a manner opposite to each other. Hence, it is worth investigating the effect of thyroid hormones on expression and functioning of SMP30 gene in breast cancer cells in which programmed cell death is deregulated. Additionally, we observed downregulation of SMP30 expression in rat liver by thyroid hormone [42]. Interestingly; MCF-7 breast cancer cells express SMP30, which is an antiapoptotic gene.

The mechanism underlying thyroid hormone induced regulation of SMP30 level in breast cancer cells as well as the role of thyroid hormones against breast cancer cells has not been addressed. In our current study, we have attempted to explore the importance of SMP30 gene, molecular mechanism of its regulation and consequences in response to thyroid hormone treatment in MCF-7 cells. These highly metastatic breast cancer cells are found to have endogenous expression of TRs as well as SMP30. Here, we are providing promising data in support of challenging breast cancer by targeting thyroid hormone receptors which might provide enough supplementary strength to interfere breast cancer metastasis by adjuvant therapies such as Selective estrogen receptor modulators (SERMs).

\section{Results}

Downregulation of SMP30 gene in MCF-7 cell line by 3, $3^{\prime} 5$ triiodo $L$ thyronine

MCF-7 breast cancer cells express a substantially good amount of SMP30 which is a well established antiapoptotic gene. Here we have examined the effect of thyroid hormone on SMP30 gene expression both at transcriptional and translational level. Fig. 1 shows that overnight treatment of thyroid hormone downregulate SMP30 protein expression in MCF-7 cells. Although TRs are present endogenously in MCF-7 cells, we over expressed them along with $\operatorname{RXR} \alpha$ to maintain appropriate amount of functionally active TRs in these breast cancer cells. It is known that thyroid hormone receptors can bind to a TRE as monomers, as homodimers or as heterodimers with the RXR. Although the heterodimer affords the highest binding affinity, and is thought to represent the major functional form of the receptor, it would be interesting to analyze the effect of T3 on SMP30 expression in MCF-7 cells not transfected with RXR $\alpha$. Expression of SMP30 was significantly downregulated in presence of only TRs but there was no further repression when both TRs and RXR $\alpha$ were overexpressed as shown in Fig.1B. Overexpression of TRs and RXR $\alpha$ in MCF-7 cells were confirmed by Western blot analysis as shown in Fig. 1A, B. In addition we also demonstrated that SMP30 expression was significantly repressed at RNA level by T3 treatment in both TRs and RXR $\alpha$ overexpressed MCF-7 cells than MCF-7 mock cells by real time PCR as in (Fig. 1C, D).

\section{Identification of high affinity TR binding sites within SMP30 Promoter}

To determine whether there were any TR binding sites within human SMP30 (hSMP30) promoter, we performed an electrophoretic mobility shift assay (EMSA). We have scanned for TREs within $2 \mathrm{~kb}$ hSMP30 promoter from transcription start site. Transcription start site of hSMP30 gene was analysed by primer extension analysis as shown in Fig. S1. TRs can bind TREs as monomers, homodimers, or heterodimers with the RXR positively or negatively regulate gene expression depending on the nature of TRE and the presence of T3. TREs are generally composed of two or more TR binding half sites arranged as direct repeats 


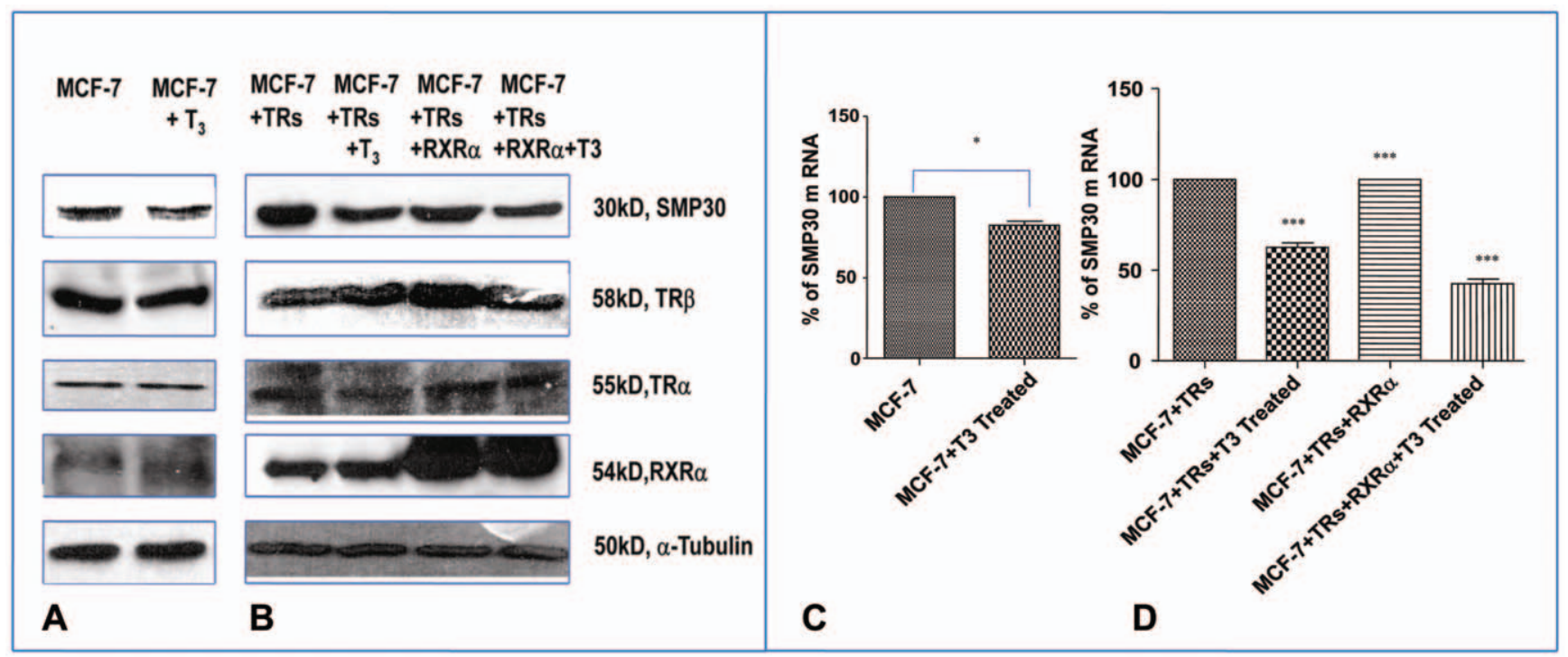

Figure 1. Downregulation of SMP30 gene in MCF-7 cell line by 3, 3'5 triiodo L thyronine. (A) Representative Western blot of total SMP30 protein in response to overnight treatment with T3 in MCF-7 cells. (B) Expressional analysis of SMP30 gene after overnight $\mathrm{T}_{3}$ treatment to TRs or TRs and RXR $\alpha$ cotransfected MCF-7 cells in Fig.1B was performed by Western blot analysis. $100 \mu \mathrm{g}$ of protein from whole cell extract was used for Western analysis.In all figures (1A and B) SMP30 protein was detected by SMP30 antibody at $\sim 30 \mathrm{kDa}$, TR $\beta$ protein was detected by TR $\beta$ antibody at $58 \mathrm{kD}$, TR $\alpha$ protein was detected by TR $\alpha$ antibody at $55 \mathrm{kD}$ and RXR $\alpha$ protein was detected by RXR $\alpha$ antibody at $54 \mathrm{kD}$ were assessed. $\alpha$-Tubulin was used as a loading control. In Fig. 1C and D, total RNA from cells were harvested and analyzed by quantitative RT-PCR. Shown are the mean values from triplicate samples normalized to GAPDH. CT values obtained from the real time PCR was used to compare the expression label of treated sample from control assuming $100 \%$ amplification. Paired student's t test performed; ${ }^{*}, P<0.01$ results were confirmed in three independent experiments as in Fig. 1C. ${ }^{* * *} P<0.0001$ difference from control using ANOVA as in Fig. 1D. doi:10.1371/journal.pone.0020861.g001

spaced by four nucleotides, palindromes without a nucleotide spacer, or inverted palindromes spaced by six nucleotides [43]. The optimal TR binding half site is the octamer TAGGTCA, an extended version of the common core response element hexamer AGGTCA [44]. In hSMP30 promoter we got two TR binding half sites i.e. at $613 \mathrm{bp}$ and $1.2 \mathrm{kbp}$ from hSMP30 transcription start site. The sequence of the former from -637 to -600 was found to be ATGTTGGTGAGGCTGGTCTCAAACTCGTGACGTTAGG and that of later from -1274 to -1235 was GAAGGACATTAAAGGGACAATTTCTATGACGTGGTG. These two DNA fragments were ${ }^{32} \mathrm{P}$-labeled, incubated with nuclear extract (N.E) of MCF-7 cells - transfected with TR $\alpha, \operatorname{TR} \beta$ and RXR $\alpha$ expression vectors. The electrophoretic mobility of the radiolabelled DNA fragments was retarded in presence of nuclear extract suggesting possible interaction between the ${ }^{32} \mathrm{P}$ labeled DNA fragments and TRs present in the nuclear extract. This binding was later confirmed by competition with 50 and 100 fold molar excess of cold self oligos, mutated and non specific oligos as shown in Fig. 2 A, B. The mobility was further retarded in presence of anti hTR $\beta$ antibodies as shown in Fig. 2 A, C, D, E but there was a clear reduction in the intensity of the TR/DNA complex upon addition of anti-TR $\alpha$ and anti $\operatorname{RXR} \alpha$ antibodies. When we were adding all the antibodies $\operatorname{TR} \alpha, \operatorname{TR} \beta$ and $\operatorname{RXR} \alpha$ together greatly diminished the major protein-DNA complex with a clear shift of band as shown in lane 7 of Fig. 2D and E. Moreover, the binding affinity of TRs to these labelled oligos of two binding sites was also decreased in presence of T3 hormone as shown in Fig. 3A. This result was further confirmed in Chromatin immunoprecipitation (ChIP) assays as in Fig. 3B. The above results clearly indicated that SMP30 promoter has specific binding sites for TRs.

\section{SMP30 Promoter in response to $T_{3}$}

We examined the response of $\mathrm{T} 3$ on transcriptional activity of $\mathrm{h} S M P 30$ promoter in MCF-7 cells by measuring luciferase activity.
We transfected reporter constructs having an oligo representative of the TREs appended to some minimal promoter along with or without expression vectors in MCF-7cells. The minimal promoter $(-684$ to -455$)$ region cloned in PGL3 basic vector is known as $\mathrm{h} S M P 30$ TRE1 and cloned $(-1290$ to -1015$)$ promoter fragment is known as hSMP30 TRE2. Luciferase activity of both the reporter vectors in MCF-7 cells having endogenous TRs did not show any significant difference in presence or absence of $\mathrm{T} 3$ where as luciferase activity was induced by over expressing TRs along with $\operatorname{RXR} \alpha$ in absence of ligand and repressed in presence of ligand as shown in Fig 4A, B. However there was no repression found in overexpressing only $\mathrm{RXR} \alpha$ by $\mathrm{T} 3$ treatment as presented in Fig. S2. Similar results were obtained using other cell line such as HEK 293 cells (as Fig.S3). The SMP30 promoter behaved similarly to those of TSH $\alpha$ [45], SOD1 gene [46], Necdin gene [47] which are negatively regulated by T3. These observations suggested that the TREs on SMP30 promoter were negatively regulated by $\mathrm{T}_{3}$.

The total luciferase expression of mutated construct of hSMP30 TRE2 (in the presence and absence of T3) was decreased as compared with wild type and the changes in the repression ratios were also small as compared with those noted with the wild type shown in Fig.4C. However, mutated hSMP30 TRE1 did not show the similar pattern. Repression was still observed although decreased luciferase activity was detected in Fig.4D. These results indicated that high affinity TR binding TREs were not necessary for T3 mediated negative regulation of SMP30 gene similar to earlier observation in case of some other genes i.e CD44 gene [48], hTSH $\beta$ [49], RSV nTRE [50,51].

To analyze the effect of TRs on hSMP30 TREs by estradiol (E2) stimulation, we did luciferase assays of hSMP30 TREs in presence and absence of E2. We found ligand independent or dependent activation of promoter activity in case of both hSMP30 TRE 1 and TRE2.However, in case of thyroid hormone treatment there was downregulation of luciferase activity as shown in Fig. 4E and F. 

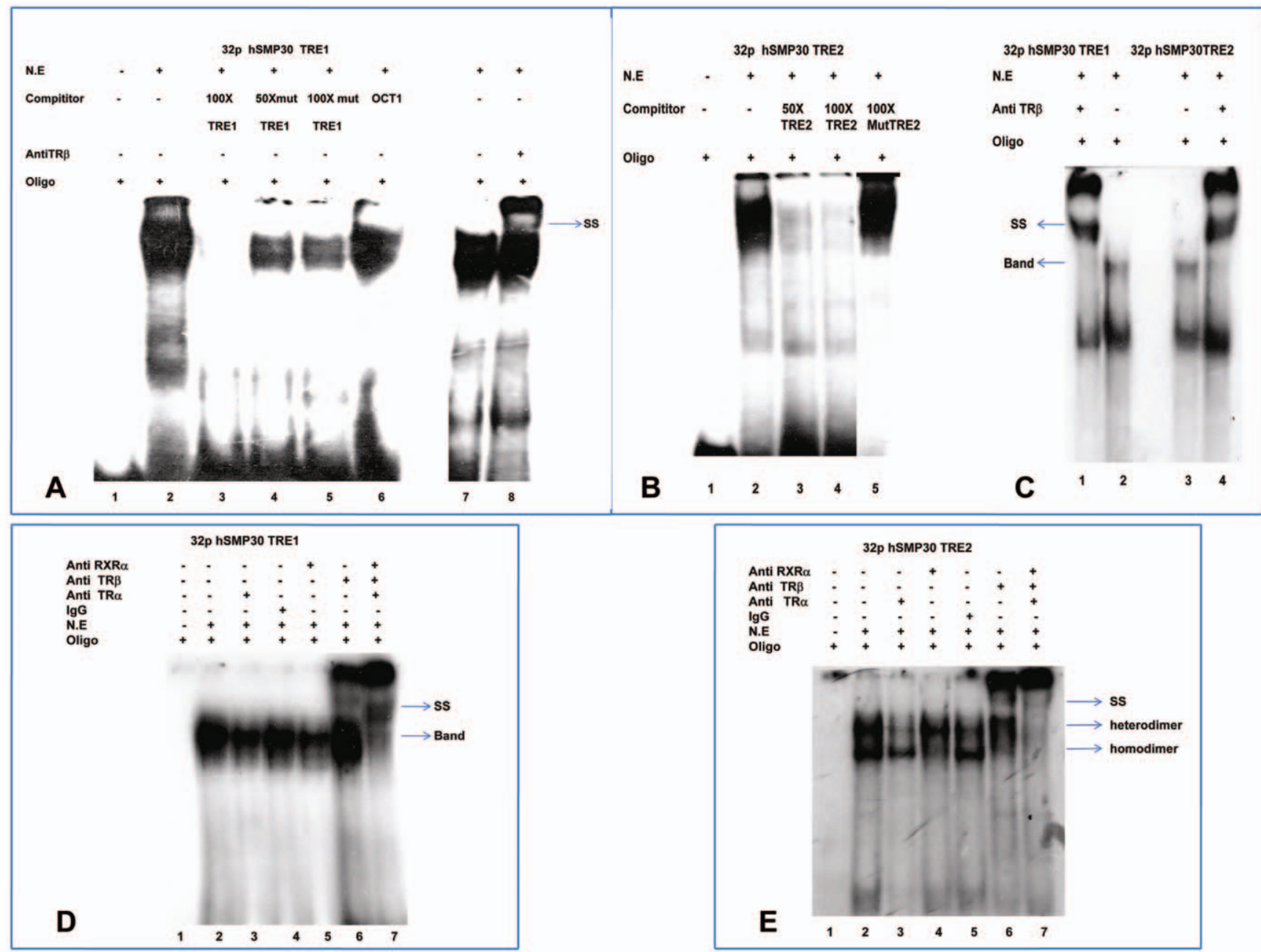

Figure 2. Identification of high affinity TR binding sites within h SMP30 Promoter. (A) Electrophoretic mobility shift assay for hSMP30 TRE1 to confirm the binding of TR. lane 1, labeled hSMP30 TRE1; lane 2, 7 are labeled hSMP30 TRE1 with $10 \mu \mathrm{g}$ of Nuclear Extract (N.E.); lane 3-6 describe competition with 100 fold molar excess of self oligo, 50 and 100fold molar excess of mut TRE1 oligo, nonspecific oligo and lane 8 antibody shift with TR $\beta$ antibody. (B) Electrophoretic mobility shift assay for hSMP30 TRE2 to confirm the binding of TR. Lane 1, labeled hSMP30 TRE2 with $10 \mu \mathrm{g}$ nuclear extract (N.E); Lane 2-4 describe competition with 50 and 100 fold molar excess of self oligo and mutated TRE2 oligo. (C) As antibody shift was not distinct for short run i.e. for 1 hour, we did long run for two hours, then we got distinct antibody shift in fig. 2C. Lane 2 and 3 are labeled hSMP30 TRE1 and TRE2 with $10 \mu \mathrm{g} \mathrm{N.E;} \mathrm{Lane} 1$ and 4 are antibody shift with TR $\beta$ antibody. (D, E) To confirm the binding of TR $\beta$ is specific to hSMP30 TRE1 and TRE2, we did electrophoretic mobility shift assay in presence of control lgG, TR $\alpha$, TR $\beta$ and RXR $\alpha$ antibodies. Lane 1 labeled hSMP30 TRE1 and TRE2; lane 2 labeled hSMP30 TRE1 and TRE2 in presence of $10 \mu \mathrm{g}$ of N.E of MCF-7 cells - transfected with TR $\alpha$, TR $\beta$ and RXR $\alpha$ expression vectors; lane 3, 4, 5, 6 antibody shift with TR $\alpha$, normal Rabbit lgG, RXR $\alpha$ and TR $\beta$ respectively; lane 7 labeled hSMP30 TRE1 and TRE2 in presence of $10 \mu \mathrm{g}$ of N.E incubated with $T R \alpha, T R \beta$ and $R X R \alpha$ antibodies in a single reaction. Arrows indicate retarded and supershifted complexes. doi:10.1371/journal.pone.0020861.g002

Luciferase activity of both the reporter vectors hSMP30 TRE1, TRE2 in MCF-7 cells having endogenous TRs did not show any significant difference in presence or absence of T3 where as luciferase activity was induced by over expressing $\mathrm{TR} \alpha$ in absence or presence of ligand. However there was significant repression found while overexpressing only TR $\beta$ in presence of ligand as presented in Fig. $4 \mathrm{G}$ and $\mathrm{H}$. These results indicate that $\mathrm{h} S M P 30$ promoter responds to exogenous expression of TR $\beta$ and this effect is synergized by $\mathrm{T} 3$ through further repressing the promoter activity.

\section{Effects of the HDAC inhibitor TSA, on T3 mediated hSMP30 repression}

$\mathrm{T}_{3}$ is known to recruit HDACs to the thyrotropin releasing hormone $(\mathrm{TRH})$ and thyroid stimulating hormone TSH $\beta$ promoters during ligand dependent negative regulation. Hence, histone deacetylation may also be an important mechanism for the negative regulation of other target genes by $\mathrm{T}_{3}$ [32 and 52].

We therefore examined the effects of the histone deacetylase inhibitor TSA, on $\mathrm{T}_{3}$ mediated SMP30 repression in MCF-7 cells by referring the following papers [32,47]. The ligand dependent and independent transcriptional activation of the SMP30 reporter construct was abolished when TSA was added as shown in Fig 5A, B.

Effect of TSA on SMP30 gene expression in MCF-7 cells was analysed both at RNA and protein level by RT-PCR and Western Blot analysis in Fig. 5C, D and E. $\mathrm{T}_{3}$ treatment resulted in repression of SMP30 gene expression by $40 \%$ and TSA further repressed SMP30 expression by $20 \%$ as here in Fig. 5E. These results suggested that $\mathrm{T}_{3}$ dependent histone acetylation of SMP30 promoter has an important role in regulation of SMP30 gene 


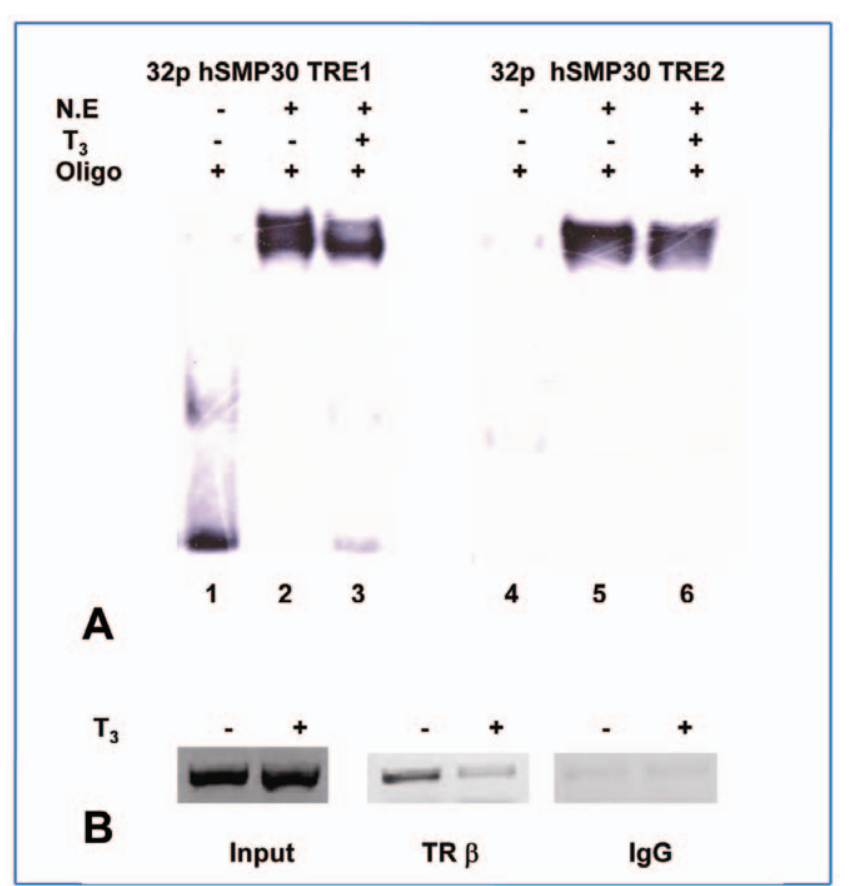

Figure 3. Effects of $T_{3}$ on TR-DNA interaction. (A) Electrophoretic mobility shift assay for hSMP30 TRE 1 and 2 in presence of $T_{3}$ hormone. Lane 1, 4 are labeled hSMP30 TRE 1 and 2 respectively. Lane 2, 5 are labeled TREs with $10 \mu \mathrm{g}$ of N.E., Lane 3, 6 are labeled TREs with $10 \mu \mathrm{g}$ of N.E in presence of $1 \mu \mathrm{M} \mathrm{T}_{3}$ hormone. (B) TR $\beta$ binding to SMP30 promoter is affected by $\mathrm{T}_{3}$ treatment was shown in ChIP. After $1 \mathrm{hr}$. treatment with $1 \mu \mathrm{M} \mathrm{T}_{3}$, MCF-7 cells were crosslinked with $1 \%$ formaldehyde and ChIP assays were performed according to manufacturer's protocol (Upstate Biotechnology) with some minor modifications. After reverse crosslinking by heating the samples at $65^{\circ} \mathrm{C}$ for 4- $6 \mathrm{hrs}$ and treating with proteinase $\mathrm{K}$, DNA was elute by phenol chloroform extraction then ethanol precipitation. PCR was performed to visualize the enriched DNA fragments. In vivo association of TR $\beta$ protein complex with the hSMP3O promoter was demonstrated by the amplification of hSMP3O TREs specific DNA fragments from chromatin complexes precipitated by antibodies for TR $\beta$. doi:10.1371/journal.pone.0020861.g003

expression. The above results also imply that deacetylation did not affect T3 dependent silencing of transcription of the SMP30 promoter, but instead was involved in the ligand independent activation, thus reinforcing the differences in the mechanisms behind TR dependent transcriptional regulation of negative thyroid response element (nTREs) vs positive thyroid response element ( pTREs).

\section{Recruitment of Cofactors to SMP30 promoter after $T_{3}$ treatment}

We next investigated the cofactors that participated in the $\mathrm{T}_{3}$ dependent histone acetylation of SMP30 promoter by ChIP analysis (Fig.6). It was found that TR $\beta$ can bind to SMP30 promoter irrespective of the presence or absence of $\mathrm{T}_{3}$, but its binding affinity was decreased in the case of former. Here we have measured the binding affinity of thyroid receptor to $S M P 30$ promoter as a result of changes in the steady state level of the TR bound to DNA across a population of cells. The above finding suggested that interaction of unknown thyroid receptor associated proteins to thyroid receptor bound to negative thyroid response elements were required for the cooperative repression. We examined the recruitment of different cofactors like HDAC3, HDAC2, HDAC1, NCoR and Steroid receptor coactivator (SRC-1) to nTREs by ChIP assays (Fig.6A). Location of primers used in ChIP assays are shown in Fig. 6B.
Quantitative real-time PCR of ChIP products were used to compare the amplification of bound DNA by different antibodies sample from input control assuming $100 \%$ amplification was shown in Fig.6C and D. There was no further recruitment of HDAC3, HDAC2, NCoR, and HDAC1 on SMP30 promoter after $\mathrm{T}_{3}$ treatment. However, binding of SRC-1 increased with $\mathrm{T}_{3}$ treatment on hSMP30 TRE2 but the same was decreased in hSMP30 TRE1 in accordance with the reduced binding of TR $\beta$ to SMP30 TREs. But, affinity of SRC-1 to bind TR $\beta$ was found to increase with $\mathrm{T}_{3}$ treatment as shown in Co Immunoprecipitation (CoIP) Fig. 7A, B. The above observations indicate that histone acetylation of SMP30 promoter after T3 treatment involves SRC-1 recruitment.

\section{TR $\beta$ enhances TR- mediated Basal Transactivation of the SMP30 Gene}

Among the two known isoforms of thyroid receptor, TR $\beta$ is reported to play a determining role in negative regulation of genes by thyroid hormone [53]. Therefore we examined the role of TR $\beta$ in the observed negative regulation of SMP30 gene by $\mathrm{T}_{3}$. Cotransfection of hSMP30 TRE1 and hSMP30 TRE2 luciferase construct with TRs and $\mathrm{RXR} \alpha$ expression vectors resulted in increased basal transactivation of SMP30 gene in absence of $\mathrm{T}_{3}$. However, in presence of $\mathrm{T}_{3}$ the promoter activity of SMP30 returned to basal level. siRNA mediated silencing of TR $\beta$, completely abolished the basal transactivation of SMP30 (Fig. 8A, B). T3 dependent repression of SMP30 was released in cells transfected with siTR $\beta$.This result was further confirmed by Western blot analysis. There was (Fig. 8C) slight increase in SMP30 protein expression in the cells transfected with siTR $\beta$ compared to scrambled siRNA transfected control cells indicating an important role of TR $\beta$ in T3 mediated negative regulation of SMP30.

\section{Effects of histone acetyl transferase (HAT) inhibitor on SMP30 promoter transcriptional activity}

Our ChIP results using antibodies against histone acetylated lysine at 18position $(\mathrm{H} 3 \mathrm{~K} 18)$ revealed histone acetylation of SMP30 promoter was increased after $\mathrm{T}_{3}$ treatment. $\mathrm{T} 3$ causes an increase in acetylation of $\mathrm{H} 3 \mathrm{~K} 9$ and $\mathrm{H} 3 \mathrm{~K} 18$ but does not affect acetylation of H3K14 where as H3K27 is deacetylated after T3 treatment [54]. An overall increase in acetylation of $\mathrm{H} 3$ leads to negative regulation of TSH $\alpha$ promoter [54]. Our specific finding of distinct recruitment of SRC-1 onTRE2 due to the enhanced association of SRG-1with $\mathrm{TR} \beta$ in response to T3 signaling as evidenced in Co-IP experiments made out a definitive mechanism behind the repression of SMP30 gene expression. Distinct withdrawal of SRC-1 from TRE1 supports for the possibility that another cofactors with HAT activity may participate in the negative regulation of SMP30 gene expression. To further examine the role of coactivator SRC-1 in mediating negative regulation, we examined the effects of HAT inhibitor CPTH-2- [cyclopentylidiene-[4-(4'- chlorophenyl) thiazol-2-yl)hydrazone] on SMP30 promoter transcriptional activity. CPTH-2, a known modulator of Gcn5 network [55] increased basal transcription levels in presence and absence of $\mathrm{T}_{3}$, presumably by decreasing histone acetylation as shown in (Fig.9A, B, C and D). These results provide further evidence for the importance of coactivator SRC-1 recruitment in mediating negative regulation of the SMP30 gene even though basal levels may be determined by overall histone acetylation.

\section{Hormonal repression of SMP30 induces apoptosis in MCF-7 cells}

Finally, we investigated whether induction of apoptotic death in MCF-7 cells by thyroid hormone is mediated through down 

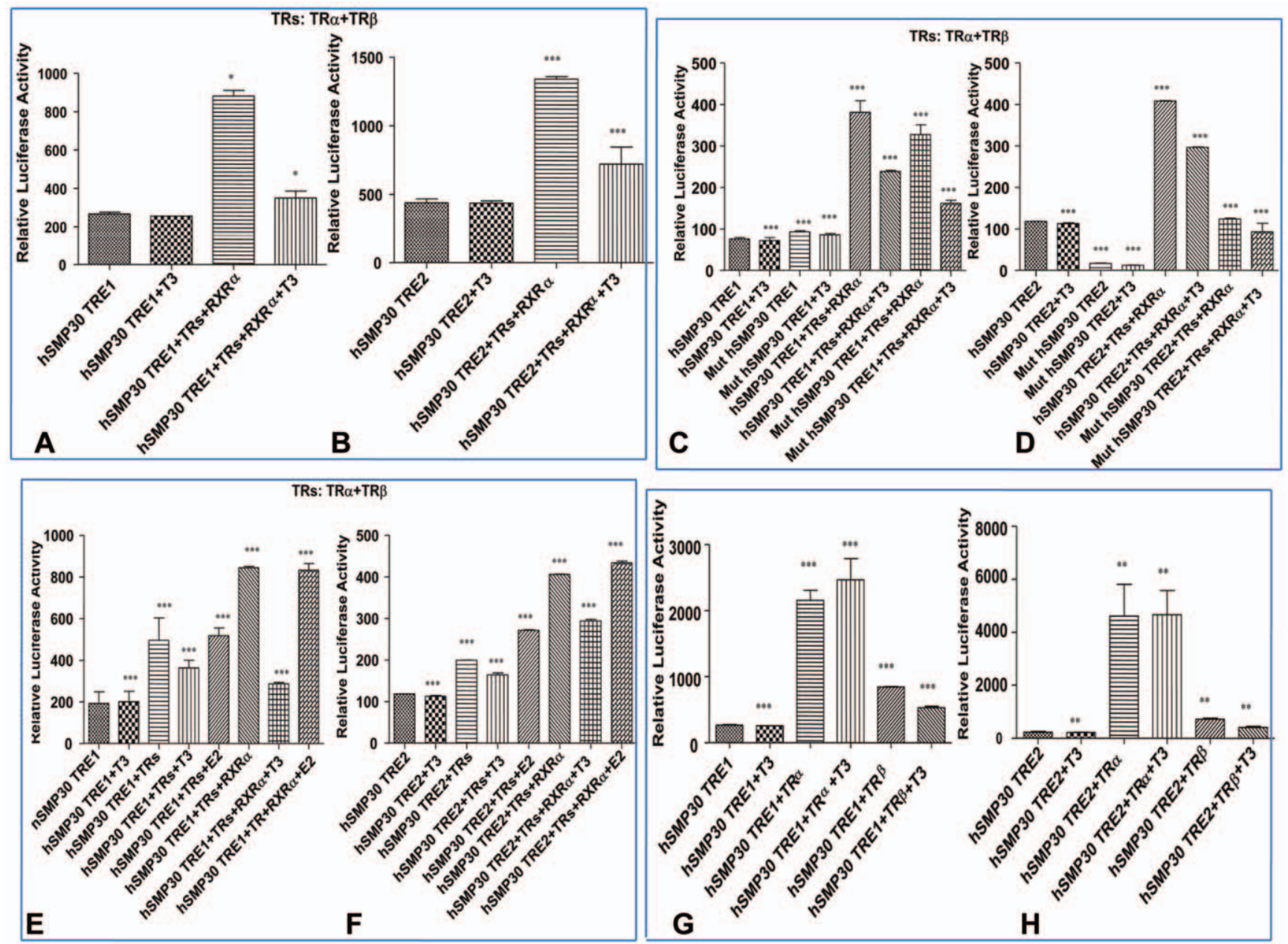

Figure 4. SMP3O Promoter in response to $\mathbf{T}_{\mathbf{3}}$. Transient transfections of $h S M P 30$ TRE1, TRE2 (A, B, E, F, G, H) and mut hSMP30 TRE1 and TRE2 (C, D) were carried out using MCF-7 cells and similar experiments were also carried out in HEK 293T cell line as shown in Fig.S3. 20 hrs before transfection, cells were plated in DMEM $10 \%$ CS media, at a density of $1 \times 10^{5}$ cells per well in 12 well plates. For transient transfection, $0.5 \mu \mathrm{g}$ of reporter plasmid DNA, $0.5 \mu \mathrm{g}$ of TR $\beta$ and TR $\alpha$ (TRs), RXR $\alpha$ expression vector or $\mathrm{pCMV}$ vector in $(\mathrm{A}, \mathrm{B}, \mathrm{C}, \mathrm{D}, \mathrm{E}, \mathrm{F}), 0.5 \mu \mathrm{g}$ of only TR $\beta$ or TR $\alpha$ expression vector or pCMV vector in $(\mathrm{G}, \mathrm{H}), 50 \mathrm{ng}$ of ${ }_{\mathrm{p}} \mathrm{RL}-\mathrm{TK}$ control vector were co transfected using Fugene HD transfection reagent (from Roche) as per manufacture's instruction. After 2 hrs of transfection, cells were subjected to overnight treatment with $1 \mu \mathrm{M}$ concentrations of $T_{3}(A, B, C, D, G, H)$, $10 \mathrm{nM}$ of E2, $1 \mu \mathrm{M}$ of T3 or ethanol vehicle to cells $(\mathrm{E}, \mathrm{F})$ in $10 \% \mathrm{CS}-\mathrm{DMEM}$. Then cell lysates were prepared and luciferase activities were measured. Values are the mean of three independent experiments \pm SD normalized to Renilla activity. ${ }^{*} P<0.0232$ difference from control using ANOVA for Fig $A$, ${ }^{* * *} P<0.0001$ difference from vehicle control using ANOVA in Fig. $B, C, D, E, F$ and $G,{ }^{* *} P<0.001$ difference from vehicle control using ANOVA in Fig. $\mathrm{H}$.

doi:10.1371/journal.pone.0020861.g004

regulation of SMP30 expression. Compared to untreated control, thyroid hormone treatment enhanced the proportion of MCF-7 cells undergoing apoptosis by $50-60 \%$ (Fig.10). Overexpression of SMP30 in MCF-7 cells lowered the proportion of apoptotic cells below the basal level (Fig. 10A, C) and knocking down of endogenous SMP30 further enhanced the induction of apoptosis by $20-30 \%$ (Fig. 10B, D). Further, Western blot analysis revealed that cleavage of, Poly (ADP Ribose) Polymerase (PARP) an indicator of caspase activation in SMP30 siRNA transfected thyroid hormone treated cells was more in comparison to untreated as well as only thyroid hormone treated cells (Fig. 10D). Similarly, PARP cleavage was found to decrease in SMP30 transfected thyroid hormone treated cells compared to only thyroid hormone treated cells (Fig. 10C). Taken together, the above results clearly suggest that down regulation of SMP30 has an important role during thyroid hormone induced apoptosis in MCF-7 breast cancer cells.

\section{Discussion}

Recent findings indicate that epigenetic alterations of the genome such as acetylation/ deacetylation and other modifications of histones prove to be key factors in breast carcinogenesis [56]. These modifications are quite interesting as targets from therapeutic point of view. Various studies have established that deregulation of hormonal signaling can be correlated to notable epigenetic alterations [57]. The proapoptotic potential of the thyroid hormone has been advocated with evidence by several research findings. [34, 35 and 36]. MCF-7 cells represent one of the few well defined breast cancer cell lines with endogenous expression of TRs [25]. Interestingly, in MCF-7 cells we observed substantially good amount of expression of SMP30 which is well established as an anti-apoptotic gene. The responsiveness of SMP30 gene to T3 signaling has been reported in an investigation in mouse model [42]. Another recent study demonstrated negative regulation of 

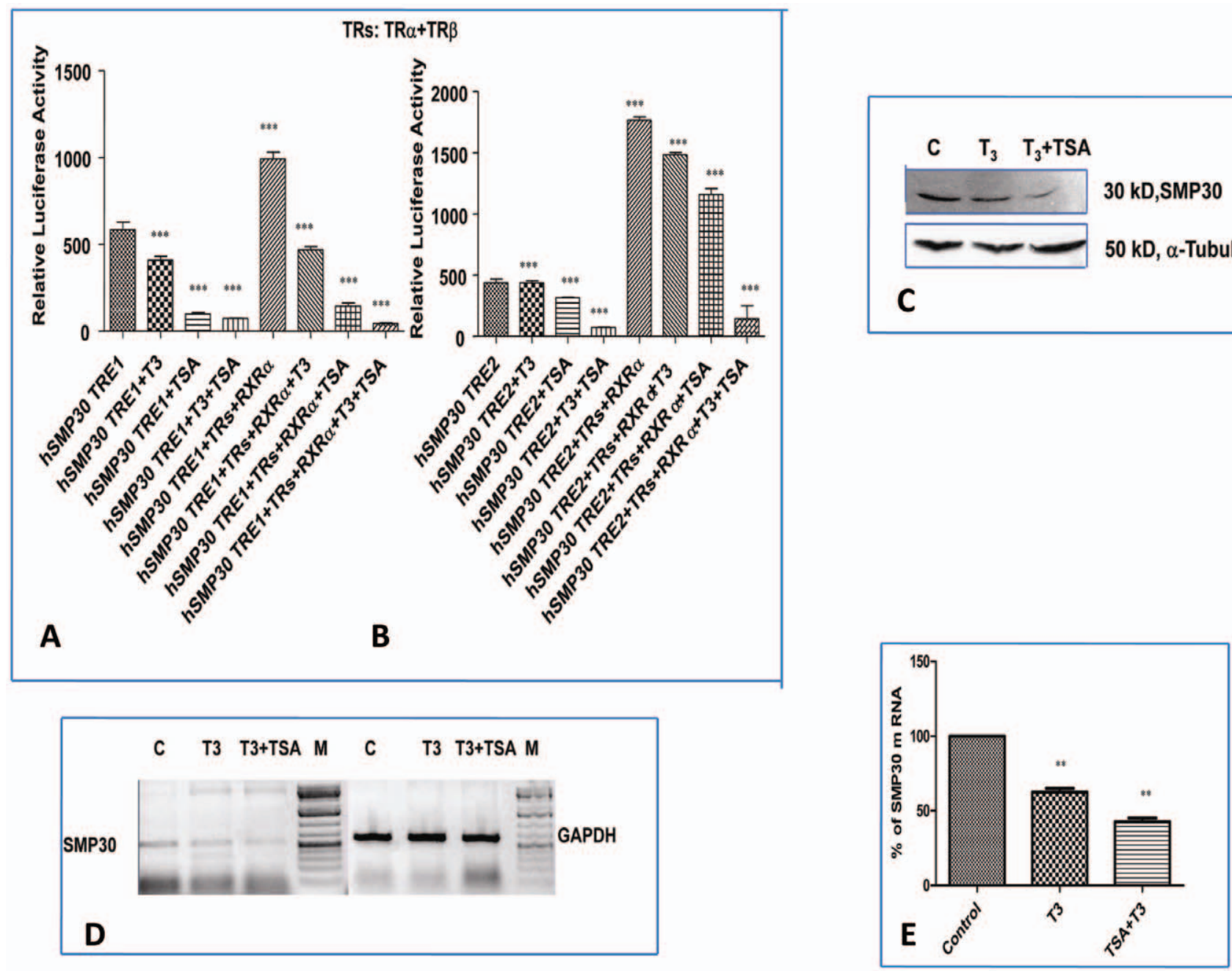

Figure 5. Effects of the HDAC inhibitor TSA, on T3 mediated hSMP30 repression. (A, B)After 24 hrs of transfection as described above, cells were subjected to overnight $(1 \mu \mathrm{M}) \mathrm{T}_{3}$ treatment followed by 6 hrs incubation in $330 \mathrm{nM}$ of TSA or ethanol vehicle to control cells. Cell lysates were prepared and luciferase activities were measured. Values are the mean of three independent experiments \pm SD normalized to Renilla activity. *** $P<0.0001$ difference from vehicle control using ANOVA in Fig. A and B. (C, D, E) Expressional analysis of SMP30 gene after T and TSA treatment to MCF-7 cells was analysed by RT-PCR, Western blot analysis and real time PCR. RT-PCR and Real time PCR were preformed as described previously. Western blot analysis was carried as described previously. In Fig. C, SMP30 protein (upper panel) band at $\sim 30 \mathrm{kDa}$ was detected by SMP30 antibody. $\alpha$-Tubulin (lower panel) was used as a loading control. A representative RT-PCR data has shown in Fig. D. SMP30 gene (left panel) and GAPDH gene in (right panel) using CDNA from MCF-7 control cells, T3 treated and T3+TSA treated cells. Same cDNA was used for quantitative RT-PCR as in Fig. E. Shown are the mean of triplicate samples (mean \pm SD) normalized to GAPDH. CT values obtained from the real time PCR was used to compare the expression label of treated sample from control assuming $100 \%$ amplification. Results were confirmed in three independent experiments. ** $P<0.0029$ difference from control using ANOVA.

doi:10.1371/journal.pone.0020861.g005

$\mathrm{TSH} \alpha$ gene as a result of T3 signaling [45]. On the basis of the above findings in our current approach, we decided to use MCF-7 as a model cell line of breast cancer to study the effect of thyroid hormones with reference to SMP30 gene.

In the current study our investigation by flow cytometry revealed that in response to thyroid hormone treatment, apoptosis could be induced in MCF-7 cell line as a result of down regulation of SMP30 gene expression. In an effort to unravel the underlying mechanism, we performed primer extension analysis to find out the transcription start site of human SMP30 (hSMP30) gene, scanning of hSMP30 promoter for TRE sites followed by gel retardation assays. On the basis of these experiments we confirmed that there are two important putative TREs at $613 \mathrm{bp}$ as (hSMP30 TRE1) and $1.2 \mathrm{kbp}$ (hSMP30 TRE2) from hSMP30 transcription start site. The luciferase assays which were conducted by taking different deletion constructs of hSMP30 promoter validated our findings of the putative TRE sites. Looking at the distinct repression caused by liganded TRs (through T3) in Fig. 1, we interpreted that activated TRs play a significant role in downregulating human SMP30 gene. Similar to our line of study, Guigon et al (2011) have identified STAT-5 as a downstream key molecule in the aberrant thyroid hormone signaling emerging out of mutated TR $\beta$. As the consequence of this the mice is predisposed to development of mammary tumors [23]. T47D human breast cancer cell line which is also ER+ve has been used in the above studies. In their investigations remarkable repression of reporter vectors as well as protein were obtained by exogenously transfected TR $\beta$ like others similar interesting study. In our current study also significant repression of reporter vectors as well as SMP30 protein were observed by transfecting $\operatorname{TR} \beta$. These results indicated that 

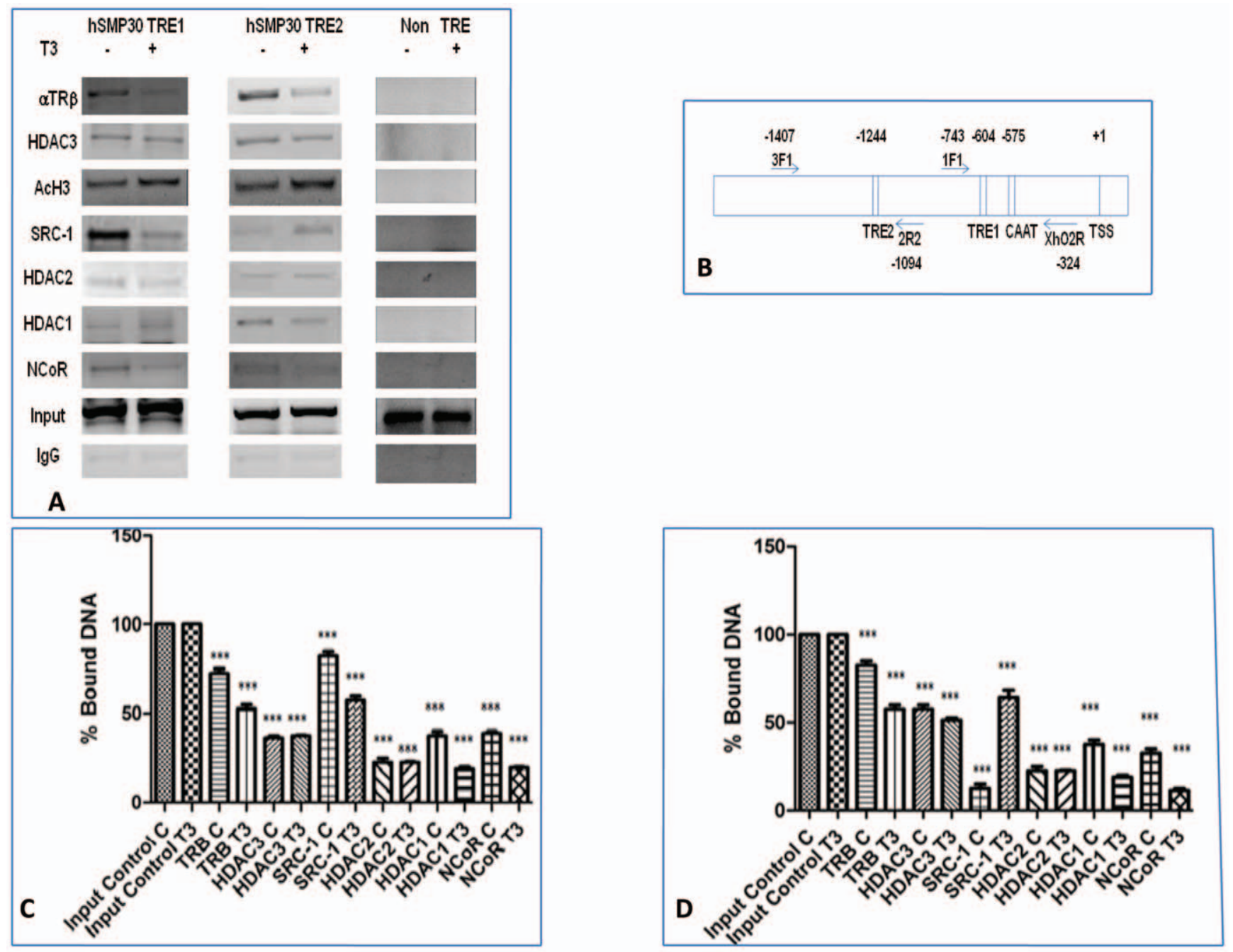

Figure 6. Recruitment of Cofactors to SMP30 promoter after $\mathbf{T}_{\mathbf{3}}$ treatment. (A) Corepressor complex and coactivator binding to minimal SMP30 promoter fragment having TREs and of the control regions having non TREs were analysed by ChIP assays. MCF-7 cells were crosslinked with $1 \%$ formaldehyde after 1 hour addition of T3, and ChIP assays were performed according to manufacturer's protocol (Upstate Biotechnology) with some minor modifications. After reverse crosslinking by heating the samples at $65^{\circ} \mathrm{C}$ for $4-6 \mathrm{hrs}$ and treating with proteinase $\mathrm{K}$, DNA was elute by phenol chloroform extraction then ethanol precipitation. In vivo association of theses protein complexes with the hSMP30 promoter was demonstrated by the amplification of hSMP30 TREs specific DNA fragments from chromatin complexes precipitated by antibodies for TR $\beta$, HDAC3, HDAC2, HDAC1, NCoR, anti-acetyl H3 antibody(H3K18) and SRC-1. Specific primers for detection of respective regions (TRE1, -744 to $-324 ;$ TRE2, -1407 to -1094 ; non TRE, -344 to +67 ) were represented. Similar results were obtained in multiple independent experiments. (B) Diagram of human SMP30 promoter and location of primers in ChIP assays. Two thyroid response elements are located at -604 and -1244 position of hSMP30 gene from transcription start site (TSS). The upstream primer (1F1) for TRE1 started at $-743 \mathrm{bp}$ and the downstream primer (Xho2R) started at -324 from TSS of hSMP30 gene. The forward primer (3F1) of TRE2 started at $-1407 \mathrm{bp}$ and the reverse primer (2R2) started at -1094 bp from TSS of hSMP30 gene. Primers denoted by arrows and name of each primer are written within a box. CAAT represent the CAAT box. (C, D) Quantitative realtime PCR of ChIP products were carried out by taking same sets of primers as conventional PCR and confirmed that the set of the primers for the realtime PCR yielded a single peak in the 40-cycle procedure. CT values obtained from the real time PCR was used to compare the amplification of bound DNA by different antibodies sample from input control assuming $100 \%$ amplification. Values are the mean (mean \pm SD) normalized to input levels were compared with those obtained with lgG for at least three independent experiments. ${ }^{* * *} P<0.0001$ difference from control using ANOVA. doi:10.1371/journal.pone.0020861.g006

TR $\alpha$ may be important for full activation of nTREs in the absence of T3, possibly by stabilizing interaction with other intermediary factors. But it may be noted with emphasis that it is not important for T3 dependent repression of SMP30 transcription. The above findings revealed that hSMP30 promoter responds to exogenous expression of TR $\beta$ and this effect was synergized by T3 through further repressing the promoter activity. Silencing of TR $\beta$ in MCF-7 cell line reduced the amount of repression as a result of T3 treatment both in terms of protein as well as promoter activity.

The total luciferase expression of mutated construct of hSMP30 TRE2 (in the presence and absence of T3) was decreased as compared with wild type and the changes in the repression ratios were also small as compared with those noted with the wild type. From this it is quite clear that the decrease in the repression might be due to decrease binding affinity of mutated TREs with TRs. However, mutated hSMP30 TRE1 did not show the similar pattern. Repression was still observed although decreased luciferase activity was detected. In summary, these results indicated that high affinity TR binding TREs were not necessary for T3 mediated negative regulation of SMP30 gene. In literature one hypothesis suggests that indirect involvement of TR in T3 mediated negative regulation is through the squelching of coregulators from other 


\section{Co Immunoprecipitation (CoIP)}

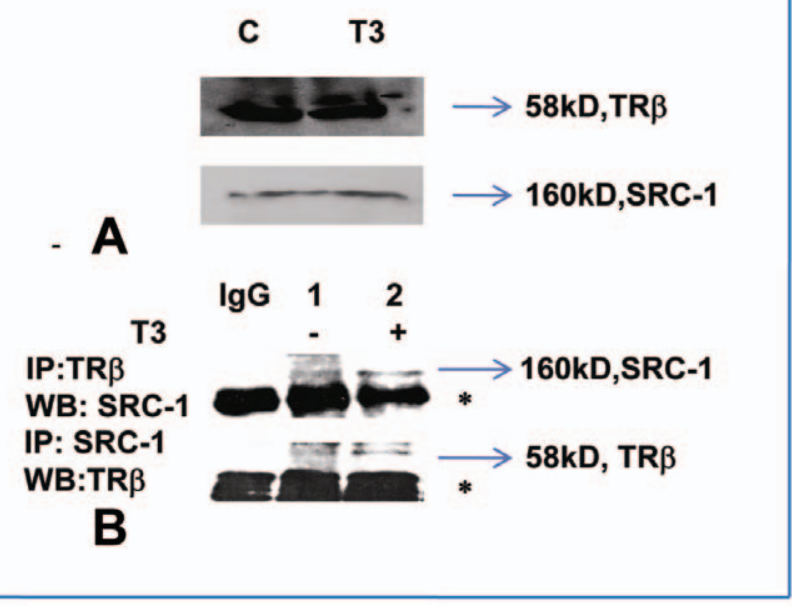

Figure 7. Effects of thyroid hormone on endogenous protein complexes were detected by Co-immunoprecipitation. (A, B) MCF-7 cells were plated in $10 \%$ CS DMEM, next day cells were subjected to overnight $(1 \mu \mathrm{M}) \mathrm{T}_{3}$ treatment. One hundred microgram of whole cell extracts were resolved in SDS-PAGE followed by Western blot analysis as shown in Fig.4E. In Fig.4F, $500 \mu \mathrm{g}$ of whole cell extracts were precipitated with TR $\beta$, SRC-1 and with normal IgG antibodies. Then precipitated proteins were eluted from protein $A / G$ plus sepharose beads separated by SDS-PAGE, and analyzed by Western blotting (WB). Asterisks denote IgG heavy chain band in upper panel and IgG light chain band in lower panel.

doi:10.1371/journal.pone.0020861.g007

transcription factors [29]. The findings were in line with the observations made in the studies of $\mathrm{T} 3$ mediated negative regulation of different genes like CD44 [48], hTSH $\beta$ [49], RSV nTRE [50,51]. The results of the experiments, carried out with estrogen signaling, further confirmed our claim that the repression of SMP30 is T3 specific.

The supershift assay performed in presence of $\operatorname{TR} \alpha, \operatorname{TR} \beta$ and $\operatorname{RXR} \alpha$ antibodies indicated that $\operatorname{TR} \beta$ has direct binding affinity for both TRE1 and TRE2. However, it might be possible that $\mathrm{TR} \alpha, \mathrm{TR} \beta$ and $\mathrm{RXR} \alpha$ protein forms a heterodimer complex then binds to thyroid response elements of both the sites present in $\mathrm{h} S M P 30$ promoter.

On the basis of our results we interpreted that thyroid response elements cannot be categorically classified as absolute positive or absolute negative elements. However by considering acetylation of histone i.e $\mathrm{H} 3$ as bench mark for the above classification we concluded that both TRE1 as well as TRE2 in SMP30 promoter are negative response element in the context of liganded TRs. By observing both the TREs differentially regulated by TRs we would like to further distinguish them on the basis of different cofactors recruitment on those TREs after T3 treatment. Our specific finding of distinct recruitment of SRC-1 on TRE2 due to the enhanced association of SRC-1with TR $\beta$ in response to T3 signaling as evidenced in [46] and also shown in Co-IP experiments made out a definitive mechanism behind the repression of SMP3O gene expression. Distinct withdrawal of SRC-1 from TRE1 supports the possibility that another coregulator/s with HAT activity may participate in the negative regulation of SMP30 gene expression. Previous studies in SRG-1 knockout mice and TR $\beta$ activation function-2 domain mutant knock in mice suggest that coactivators may be important for negative regulation of genes [58, 59, 60 and 61]. In our investigation another interesting but opposite result was observed in the recruitment pattern of HDAC1, HDAC2 as well as NCoR on TRE1 and TRE2. These differential recruitment patterns also make our above argument more logical. Similar kinds of observations were reported for SOD1, Necdin, and CD44 - target gene that they are under negative regulation by $\mathrm{T}_{3}[46,47$ and 48$]$. We believe enhanced recruitment of $\mathrm{AcH} 3$ locally does not speak for the complete active chromatin structure. The recent reports by Wang et al $[45,54]$ about $\mathrm{TSH} \alpha$ target gene also de-link the traditional concept of enhanced histone acetylation to transcriptional activation of the gene. The above cited investigation also explained our findings of further repression of SMP30 gene by TSA (Trichostatin A) which is an inhibitor of deacetylases. The repression of SMP30 gene by liganded TRs was reversed after treatment with HAT inhibitor. From this observation it was very clear that histone acetylation played a major role in the negative regulation of SMP30 gene by liganded thyroid receptor. It also established the authenticity and importance of our characterisation of two negative thyroid response elements i.e TRE1 and TRE2 of SMP30 promoter. These observations resemble the functioning of other liganded TR mediated negative TREs (nTREs) [30]. In the above investigation Tagami et al discussed that TR mediated recruitment and basal activation by SMRT and NCoR in absence of T3 and reversal of basal activation by dissociation of corepressors in the presence of T3 [30]. On the background of these contrasting results, we advocate that the response of SMP30 promoter to T3 signaling may not be analysed in isolation with regard to either TRE1 or TRE2. Rather the repression of SMP30 gene expression is the combined outcome of the response of both the above elements to T3 signaling.

Observations in the present study revealed that thyroid hormone mediated down regulation of SMP30 was direct and accomplished through negative TREs within hSMP30 promoter. To ascertain the role of SMP30 in the thyroid hormone induced apoptosis of MCF-7 cells, we studied the effect of thyroid hormone after overexpressing and knocking down the SMP30 gene in MCF-7 cells respectively. Overexpression of SMP30 in our study resulted in reversal of thyroid hormone induced apoptosis of MCF-7 cells while knocking down of SMP30 made the cells increasingly susceptible to thyroid hormone induced apoptosis. These findings indicated anti-apoptotic role of SMP30 in MCF-7 cells which is in accordance with earlier reports regarding the role of SMP30 in literature [38-41] in other systems. We found out that apoptosis can be executed by downregulating the expression of SMP30 gene in MCF-7 cells. Interestingly, this repression was further enhanced as a result of T3 as well as TSA treatment. It is a well established fact that TSA which is a HDAC inhibitor induces apoptosis in different types of cancer [62]. It has also been reported that TSA induced apoptosis in lymphoma cells by decreasing Bcl-2 expression significantly [63]. Overexpression of HDACs increases Bcl-2 expression and inhibition of HDAC activity by HDAC inhibitor decreases its expression [63]. In the specific case we would like to bring several reports about the hypothesis and established finding about the negative thyroid response elements. It has been reported that TSA can inhibit the transcriptional activation of the mouse mammary tumor virus promoter by progesterone, suggesting histone acetylation is not always correlated with increased transcription [64]. Wang et al [45] suggested that there is a subset of thyroid hormone mediated negatively regulated genes with increased histone acetylation by microarray analysis. Because of lack of unequivocal evidence correlating TR $\beta$ with mammary tumor development a concrete 

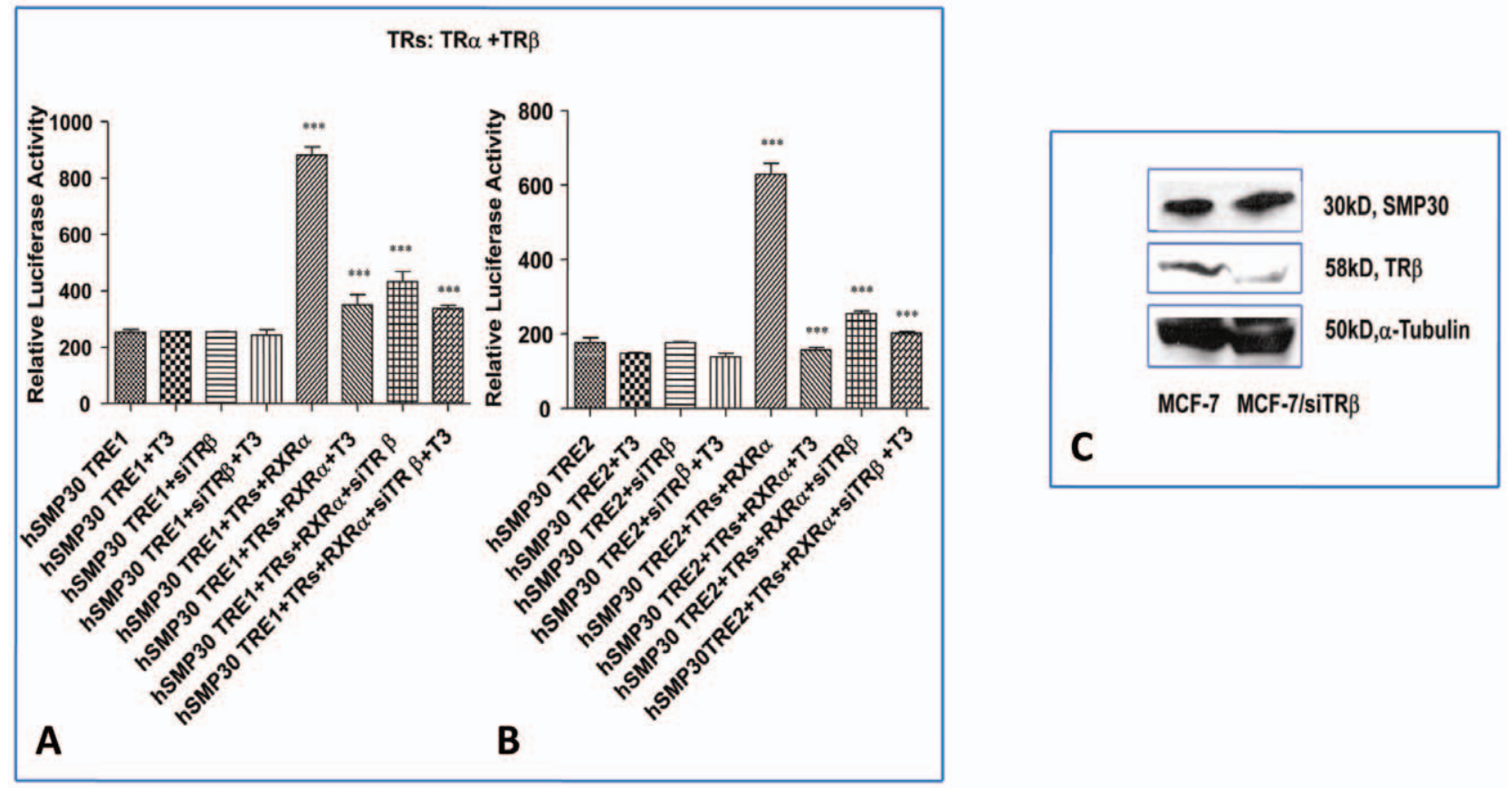

Figure 8. TR $\beta$ enhances TR- mediated Basal Transactivation of the SMP30 gene. (A, B) hSMP30 TRE1 and TRE2 reporter constructs were transfected in MCF-7 cells. 24 hrs after transfection of reporter plasmid DNA and expression vectors, 200pmole per well of TR $\beta$ siRNA or non specific scrambled siRNA (syntesized from Eurogentec) were transfected using oligofectamine according to manufacture's instruction (Invitrogen). After 24 hrs of second round transfection, cells were incubated for an additional $24 \mathrm{hrs}$ in the presence and absence of $1 \mu \mathrm{M} \mathrm{T}_{3}$, then cells were harvested for luciferase assays and readings were taken in duplicates in three independent experiments. Values are the mean of three independent experiments \pm SD normalized to Renilla activity. ${ }^{* *} P<0.0001$ difference from control using ANOVA. (C) The endogenous SMP30 expression was measured in TR $\beta$ knockdown MCF-7 cells by Western blot analysis. Decrease of TR $\beta$ expression by TR $\beta$ siRNA transfection was confirmed by Western blot analysis. Western blot analysis was carried by taking equal amount of protein from scrambled siRNA or siTR $\beta$ transfected MCF-7cells. SMP30 protein (upper panel) at $\sim 30 \mathrm{kDa}$, TR $\beta$ protein (middle panel) at $\sim 58 \mathrm{kDa}$ was detected by TR $\beta$ antibody and $\alpha$-Tubulin (lower panel) was used as a loading control. doi:10.1371/journal.pone.0020861.g008

thyroid hormone based therapy has not been developed so far. Similar to our line of observation Guigon et al (2011) have shown downregulation of STAT-5 as a result of mutation in TR $\beta$ which was manifested in terms of predisposal of the mice to the development of mammary tumors. Our current study and the emerging importance of thyroid hormone in breast cancer support our claim that why we need to seriously think for a combinatorial therapy by taking both $\mathrm{T} 3$ as well as other anticancer drugs including those related to TSA [65]. Additionally, downstream target molecules also need to be identified and thoroughly investigated for their role in inducing apoptosis or development of mammary gland tumor as a result of variable or aberrant thyroid hormone signaling. Our current study may prove to be useful for developing potent therapeutic agent to challenge the progression of breast cancer.

\section{Materials and Methods}

\section{Cell Culture}

MCF-7and HEK 293T were obtained from National Centre for Cell Sciences, Pune. They were cultured in DMEM supplemented with 10\% fetal bovine serum (FBS) mantained in 5\% $\mathrm{CO}_{2}$ atmosphere in $37^{\circ} \mathrm{C}$ until $70-80 \%$ confluent. For stimulation with $\mathrm{T}_{3}$, culture medium was removed, the cells were rinsed once with phosphate buffer saline (PBS) and medium containing $10 \%$ charcoal-stripped fetal bovine serum (CS-FBS) was added and incubation continued for 3 days. $\mathrm{T}_{3}(1 \mu \mathrm{M})$, (from Sigma) was diluted in medium and charcoal-stripped $10 \%$ fetal bovine serum was added to cells for the times indicated in figure legends.

\section{Plasmid Constructions}

hSMP30 TRE1 reporter construct was prepared by amplifying human SMP30 promoter from MCF-7 genomic DNA by using hSMP PCR 1F2 and hSMP PCR 1R1 primer sequences are shown in table 1. That amplified product, then cloned into ${ }_{\mathrm{p}}$ Blue TOPO TA vector (Invitrogen). Insert was taken out from ${ }_{\mathrm{p}}$ Blue TOPO TA vector by HindIII digestion and ligated in to HindIII digested PGL3 Basic vector to obtain hSMP TRE1 reporter construct. Similarly, hSMP TRE2 reporter construct was prepared by amplifying human SMP30 promoter from MCF-7 genomic DNA using hSMP PCR $2 \mathrm{~F}$ and $\mathrm{h} S M P$ PCR 2Rl primer sequences shown in table land then cloned in to ${ }_{\mathrm{p}}$ TARGET $^{\mathrm{tm}}$ vector. Insert was taken out from ${ }_{\mathrm{p}}$ TARGET $^{\mathrm{tm}}$ vector by digesting in Kpn I and Xho I enzyme, ligated in to digested PGL3 basic vector. RT-PCR product of human $S M P 30$ was prepared from MCF-7 cDNA by using hSMP30 EcoRI F and XhoI R primers (sequences are shown in table 1). Then that product was ligated in to digested pCMV vector using DNA ligase to make SMP30 expression vector. ${ }_{\mathrm{p}} \mathrm{CMX}-\mathrm{hRXR}-\alpha,{ }_{\mathrm{p}} \mathrm{CMX}-\mathrm{hTR} \beta$ and ${ }_{\mathrm{p}} \mathrm{CMX}-\mathrm{rTR} \alpha$ were received from Dr Ronald M Evans, The Salk Institute for Biological Studies, San Diego, CA. All constructs were confirmed by manual sequencing.

\section{Transfection and Luciferase Assay}

Transient transfections were carried out using MCF-7 cells and similar experiments were also carried out in HEK 293T cell lines. $20 \mathrm{hrs}$ before transfection, cells were plated in DMEM 10\%CS media, at a density of $1 \times 10^{5}$ cells per well in 12 well plates. For transient transfection $0.5 \mu \mathrm{g}$ of reporter plasmid DNA, $0.5 \mu \mathrm{g}$ of 

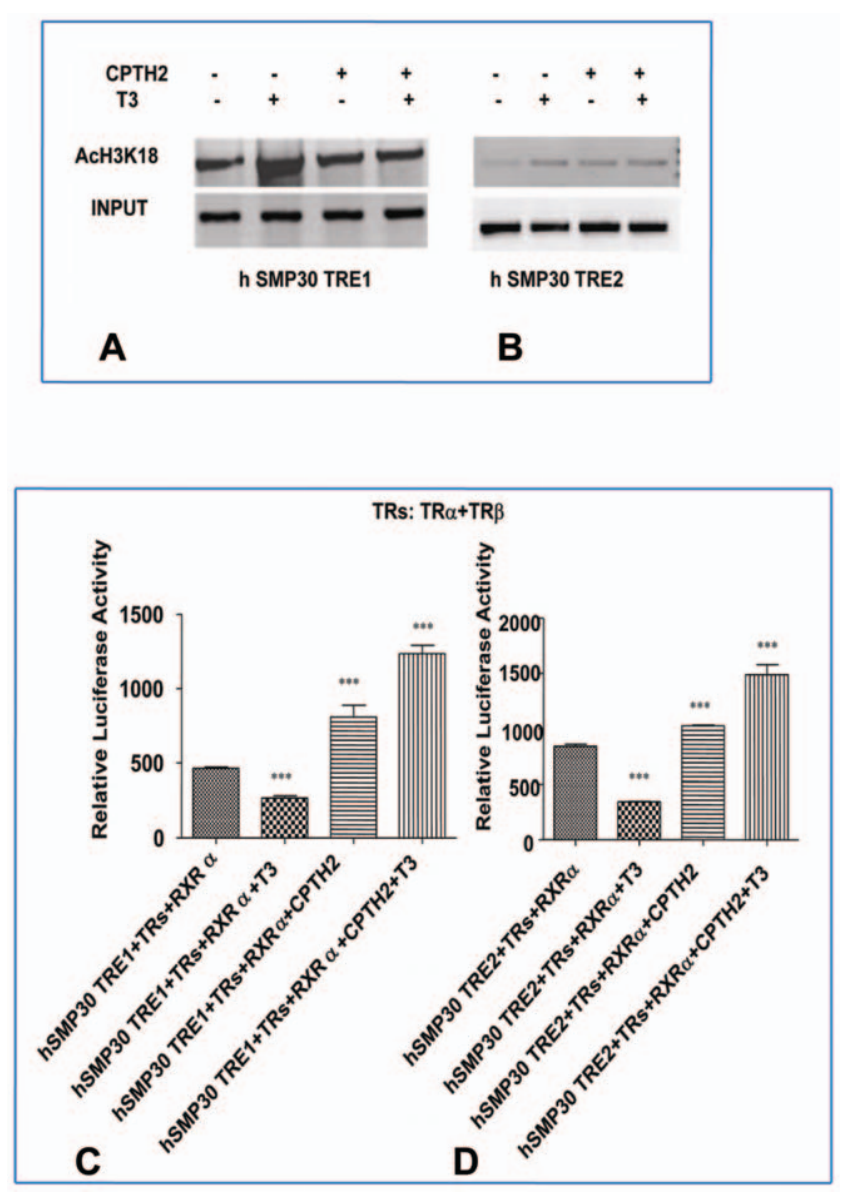

Figure 9. Effects of HAT inhibitors on SMP30 promoter transcriptional activity. (A) Effects of HAT inhibitor on acetylation of SMP30 promoter (hSMP30 TRE1 and hSMP30 TRE2) was carried out by ChIP assays using anti-acetyl $\mathrm{H} 3$ antibody (H3K18). MCF-7 cells were treated with CPTH2 for overnight followed by $1 \mu \mathrm{M}$ of $\mathrm{T}_{3}$ treatment for $1 \mathrm{hr}$ before harvesting for ChIP assays. (B) SMP30 transcriptional activity after blocking with HAT inhibitor, CPTH2. Transfection of hSMP30TRE1 and TRE2 reporter vectors along with expression vectors were carried out as described above followed by overnight treatment with $1 \mu \mathrm{M}$ of $\mathrm{T}_{3}$ and $0.05 \mathrm{mM}$ concentrations of CPTH 2 ( $24 \mathrm{hr}$ post transfection). Then cell lysates were prepared and luciferase activities were measured. Values are the mean of three independent experiments \pm SD normalized to Renilla activity. ${ }^{* * *} P<0.0001$ difference from vehicle control using ANOVA.

doi:10.1371/journal.pone.0020861.g009

$\mathrm{TR} \beta$ and $\mathrm{TR} \alpha$ as (TRs), RXR $\alpha$ expression vector or pCMV vector and $100 \mathrm{ng}$ of $\mathrm{pRL}$-TK control vector were co transfected using Fugene HD transfection reagent (from Roche) as per manufacture's instruction. After $24 \mathrm{hrs}$ of transfection $1 \mu \mathrm{M}$ T3 hormone was added and treatment of TSA and HAT inhibitor (from Sigma) were carried out accordingly as shown in figure legend. The cell lysates were prepared, and luciferase activities were measured in duplicates in three independent experiments.

\section{Transient Transfection of siRNA}

$24 \mathrm{hrs}$ after transfection of reporter plasmid DNA and expression vectors, 200 pmole of TR $\beta$ siRNA or nonspecific scrambled siRNA (syntesized from Eurogentec) per well were transfected using oligofectamine according to manufacture's instruction (Invitrogen). After $24 \mathrm{hrs}$ of second round transfection, cells were incubated for an additional $24 \mathrm{hrs}$ in the presence and absence of
$1 \mu \mathrm{M} \mathrm{T}_{3}$, then cells were harvested for luciferase assays and readings were taken in duplicates in three independent experiments.

\section{Electrophoretic mobility shift assays}

Electrophoretic mobility shift assay was performed as described in [66]. Oligonucleotides (both strands) corresponding to hSMP30 TRE sites were synthesized as shown in table 2. For each site one strand was end labelled with $\gamma^{32} \mathrm{P}$ ATP using T4 poly nucleotide kinase and annealed to its complementary unlabelled strand. Nuclear extracts of MCF-7transfected with TR $\alpha, \operatorname{TR} \beta$ and RXR $\alpha$ expression vectors $(10 \mu \mathrm{g})$ to maintain appropriate concentration of functionally active nuclear receptors were incubated with 20fmoles of radiolabelled oligonucleotide duplex and $1 \mu \mathrm{g}$ poly $(\mathrm{d}$ I-d C) in $30 \mu \mathrm{l}$ reaction mixture containing $10 \mathrm{mM}$ Tris-HCl (pH 7.5), $50 \mathrm{mM} \mathrm{NaCl}, 1 \mathrm{mM}$ DTT, 5\% glycerol for 20 mins at room temperature. In competition experiments, 100 fold molar excess of unlabeled self and mutated oligonucleotide duplexes (sequences as shown in table3) were added during pre incubation period. For antibody shift assay, control IgG (Santacruz), TR $\alpha$ (Abcam), TR $\beta$ (Abcam), RXR $\alpha$ (Santacruz) antibodies were added after addition of nuclear extract and probe, followed by incubation for 45 mins at room temperature. Free DNA and protein bound DNA was separated in 5\% non-denaturing polyacrylamide gel in 0.5x TBE. After electrophoresis, gels were blotted on to filter paper, dried and autoradiographed.

\section{Chromatin Immunoprecipitation (ChIP) Assay}

ChIP assay was performed as previously described [67]. Briefly, MCF-7 cells were grown to $90 \%$ confluence in DMEM supplemented with $10 \%$ charcoal stripped fetal bovine serum for 3days. After addition of $1 \mu \mathrm{M}$ T3 for 1 hour, ChIP assays were performed according to manufacturer's protocol (Upstate Biotechnology) with some minor modifications. After reverse crosslinking by heating the samples at $65^{\circ} \mathrm{C}$ for $4-6 \mathrm{hrs}$ and treating with proteinase $\mathrm{K}$, DNA was elute by phenol chloroform extraction then ethanol precipitation. PGR was performed to visualize the enriched DNA fragments using primers that amplify hSMP30 TRE1 (h SMP PCR 1F1 and Xho2 R), TRE2 promoter (h SMP PCR $3 F 1$ and 2R2) and non TRE region. These primer sequences were listed in table 4. Conventional PCR signals stained with ethidium bromide in 2\% agarose gel as shown in Fig. 6A.

\section{Co-immunoprecipitation assays}

Co-Immunoprecipitation (Co-IP) and western blot assays were performed as described [68]. Five hundered micrograms of MCF7 whole cell extracts were subjected to immunoprecipitation (IP) with the indicated antibodies as shown in Fig.7B and the precipitated protein complexes were subjected to Western blot analysis.

\section{Real-time PCR}

MCF-7 cells were harvested after 15 hrs of T3 followed by 6 hrs of TSA with or without treatment. RNA was isolated and SMP30 and GAPDH mRNA expression were determined by quantitative RT PCR using SYBR greensystem (SIGMA). Relative values (mean $\pm \mathrm{SD})$ normalized to GAPDH expression.

\section{RT PCR}

RT-PGR was preformed as described elsewhere [42]. The sequences of sense and antisense primer for hSMP30 were given in table 5. As a positive control, a fragment of human GAPDH cDNA was amplified by using primers were given in table 5 . The PCR condition for SMP30 was as follow: initial denaturation $\left(94^{\circ} \mathrm{C} 3 \mathrm{~min}\right),\left(94^{\circ} \mathrm{C} 45 \mathrm{~s}, 65^{\circ} \mathrm{C} 45 \mathrm{~s}, 72^{\circ} \mathrm{C} 45 \mathrm{~s}\right)$ for 30 cycles and 


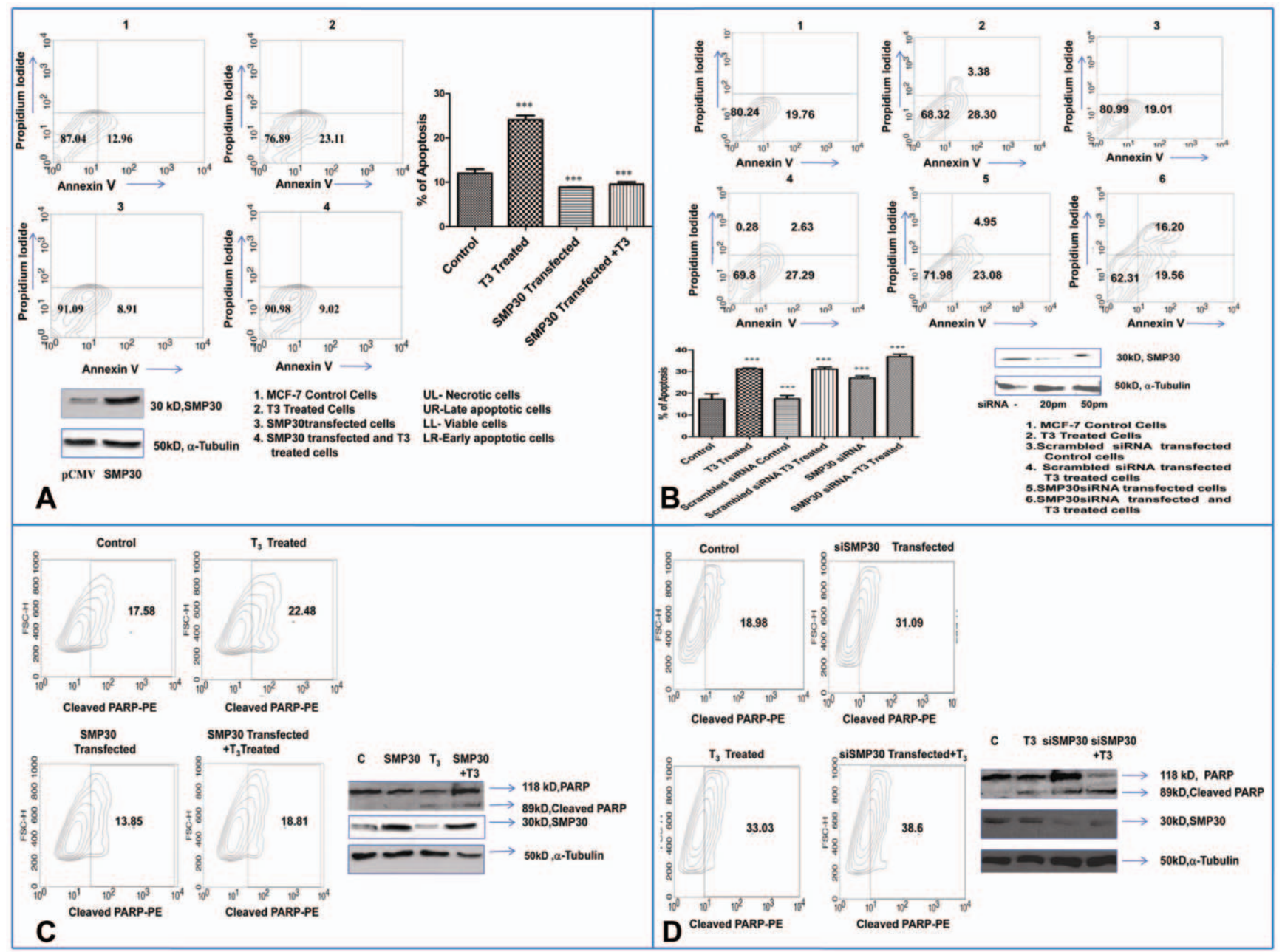

Figure 10. Hormonal repression of SMP30 induces apoptosis in MCF-7 cells. (A, B) Apoptosis was assessed by flow cytometry. MCF-7 cells transfected with mock vector (CMV-FLAG) and vector containing SMP30 gene as (SMP30-FLAG) were incubated in presence or absence of $10 \mu \mathrm{M} \mathrm{T}_{3}$ for $24 \mathrm{hrs}$ in culture. Knocking down of endogenous SMP30 expression or scambled siRNA transfected control MCF-7 cells were followed by incubation with or without $10 \mu \mathrm{M} \mathrm{T}$. After $24 \mathrm{hrs}$ of incubation cells were harvested and assayed for apoptosis using the Annexin V FITC apoptosis detection kit, IMGENEX according to manufacturer's instruction. Cells were analyzed in FACS Calibur Analyzer (Becton Dickinson) by using Cell Quest Pro software. Shown are the mean of triplicate samples \pm SD normalized to control. Similar findings were found in two other experiments, ${ }^{* * *} P<0.0001$ difference from only vector transfected control using ANOVA in Fig. $6 \mathrm{~A}$ and ${ }^{* * *} P<0.001$ difference from scrambled siRNA transfected control using ANOVA in Fig. 6B. (C, D) Detection of apoptosis was further confirmed by flow cytometry analysis of intracellularly stained MCF-7 cells with PE-conjugated polyclonal antibodies against cleaved PARP (BD Biosciences 552933) according to manufacturer's instruction. This was followed by washing with PBS twice and analysis by Flow cytometer. Percentage of population shifting right in the gate represent population of cells showing cleavage of caspase substrate PARP. Cleavage of PARP was demonstrated by Western blot analysis using anti PARP antibody (Calbiochem) taking equal amount of proteins from target cells. Cleavage PARP protein was revealed by presence of two bands, one for full length PARP (119 kD) and another for cleaved PARP (89 kD) in the Western blot. SMP30 protein (upper panel) was detected by SMP30 antibody and the protein band at $\sim 30$ $\mathrm{kDa}$ was assessed to determine the efficiency of transfection. $\alpha$-Tubulin (lower panel) was used as a loading control.

doi:10.1371/journal.pone.0020861.g010

Table 1. Primers used for cloning.

\begin{tabular}{ll}
\hline & Sequence $\mathbf{5}^{\prime}$-3' \\
\hline hSMP PCR 1F2 & CACCACGCCCGGCTAATTTG \\
hSMP PCR 1R1 & GGCAACAAAGTGAGACTTCGTCTC \\
hSMP PCR 2F & GGCAGTGCCAACATAGAAGG \\
hSMP PCR 2R1 & CTTCCTCAGTGCTGATGTCTCCC \\
hSMP30 ECoR I F & ACAGAATTCCCTGCGACCATGTCTTCC \\
hSMP30 Xho I R & ACACTCGAGTCCCGCATAGGAGTAGGGA \\
\hline doi:10.1371/journal.pone.0020861.t001
\end{tabular}

Table 2. Oligonucleotide used for EMSA.

\begin{tabular}{ll}
\hline & Sequence $\mathbf{5}^{\prime}$-'3' \\
\hline hSMP30 TRE 1 SS & ATGTTGGTCAGGCTGGTCTCAAACTCCTGACCTTAGG \\
hSMP30 TRE 1 AS & CCTAAGGTCAGGAGTTGAGACCAGCCTGACCAACAT \\
hSMP30 TRE 2 SS & GAAGGACATTAAAGGGACAATTCTATGACCTGGTG \\
hSMP30 TRE 2 AS & CACCAGGTCATAGAAATTGTCCCTTAATGTCCTTC \\
\hline doi:10.1371/journal.pone.0020861.t002
\end{tabular}


Table 3. Mutated Oligonucleotide used for EMSA.

\begin{tabular}{ll}
\hline & \\
\hline & Sequence $\mathbf{5}^{\prime}$-3' \\
\hline hSMP30 mutTRE1 SS & ATGTTAGTAAGGCTGGTCTCAAACTCCTGAAATTAGG \\
hSMP30 mutTRE1 AS & CCTAATTTCAGGAGTTGGAGACCAGCCTTACTACAT \\
hSMP30 mutTRE2 SS & GAAAGAAATTAAAGGGACAATTCTATGAAATGGTG \\
hSMP30 mutTRE2 AS & CACCATTTCATAGAATTGTCCCTTTAATTTCTTTC \\
\hline doi:10.1371/journal.pone.0020861.t003
\end{tabular}

additional extension was per formed at $72^{\circ} \mathrm{C}$ for $5 \mathrm{~min}$. The PCR condition for GAPDH as follows: initial denaturation $\left(94^{\circ} \mathrm{C}\right.$ $3 \mathrm{~min}),\left(94^{\circ} \mathrm{C} 45 \mathrm{~s}, 56^{\circ} \mathrm{C} 45 \mathrm{~s}, 72^{\circ} \mathrm{C} 45 \mathrm{~s}\right)$ for 30 cycles and additional extension was performed at $72^{\circ} \mathrm{C}$ for $5 \mathrm{~min}$. Then PCR products were electrophoresed in $1.5 \%$ agarose gel.

\section{Western Blot Analysis}

Whole cell extracts were prepared from cells and Western blotting was performed as described elsewhere [42]. $100 \mu \mathrm{g}$ of protein from whole cell extract was used for Western analysis. Goat SMP30 antibody (Santacruz) 1:500 times, cleaved PARP (Calbiochem) 1:1000 times, TR $\beta$ (Abcam) 1:1000 times, SRC-1 (Milipore) 1:2000 times, TR $\alpha$ (Abcam) 1:1000 times, RXR $\alpha$ (Santacruz) 1:1000 times dilution and their respective HRP conjugated secondary antibody (Santacruz) 1:5000times dilution were used to detect protein expression in western blot. $\alpha$ - Tubulin antibody (Santa Cruz) 1:1000times dilution was used for immunodetection of $\alpha$ - Tubulin protein, which was used as a loading control. Western Blotting Luminol Reagent kit (Amersham) was used for visualization of bands according to manufacturer's protocol.

\section{Flow cytometric analysis}

To detect intact, necrotic and apoptotic cells, flow cytometry was performed. MCF-7 cells transfected with mock vector (CMVFLAG) and vector containing SMP30 gene as (SMP30-FLAG) were incubated in presence or absence of $10 \mu \mathrm{M} \mathrm{T}_{3}$ for $24 \mathrm{hrs}$ in culture. Knocking down of endogenous SMP30 expression or non specific scrambled siRNA was followed by incubation of MCF-7 cells with or without $10 \mu \mathrm{M} \mathrm{T}$. After $24 \mathrm{hrs}$ of incubation cells were harvested and assayed for apoptosis using the Annexin V FITC apoptosis detection kit, IMGENEX according to manufacturer's instruction. Cells were analyzed in FACS Calibur Analyzer (Becton Dickinson) by using Cell Quest Pro software.

Detection of apoptosis by Annexin-V-FITG detection kit was further confirmed by intracellular staining with PE-conjugated polyclonal antibody against cleaved PARP (BD Biosciences 552 933) according to manufacturer's instruction. This was followed by

Table 4. Primers used in ChIP PCR.

\begin{tabular}{ll}
\hline & Sequence $\mathbf{5}^{\prime}$-3' $^{\prime}$ \\
\hline hSMP PCR 1F1 & GGATTCAAGCAATTCTCCTGTCTCAGCC \\
hSMP XhO2 R & ACACTCGAGACAGTCTGGGCTTTCTCC \\
hSMP PCR 3F1 & CTGCAAGACTCACGGTCTAGCAGGTCATTT \\
hSMP PCR 2R2 & CTTCCTCTACTTCCTCAGTGCTGATGTCTC \\
hSMP non TRE F & TGGAGAAAGCCCAGACTGTCAGAT \\
hSMP non TRE R & GGCTGGAAGAATCCTGCAAAG \\
\hline doi:10.1371/journal.pone.0020861.t004
\end{tabular}

Table 5. Primers used for RT- PCR.

\begin{tabular}{ll}
\hline & Sequence $\mathbf{5}^{\prime}$-3' \\
\hline hSMP30 +560 to +580 & GCCACCATTGGAACCAAGTT \\
hSMP30 +1105 to +1085 & CCCTCCAAAGCAGCATGAAG \\
hGAPDH SS2 & GATCATCAGCAATGCCTCCT \\
hGAPDH AS2 & TTCCTCTTGTGCTCTGCTG \\
\hline doi:10.1371/journal.pone.0020861.t005 &
\end{tabular}

washing with PBS twice and analysis by Flow cytometer. Percentage of population shifting right in the gate represent population of cells showing cleavage of caspase substrate PARP.

\section{Site-directed Mutagenesis}

Two bases of the TREs were mutated as shown in the table 6 (bases in bold letter represents mutated base). For mutagenesis of TREs in hSMP30TRE1 and TRE2 reporter vectors two sets of PCR were carried out using the following combination of primers: ForTRE1: hSMP PCR1F2/ hSMP mut TRE1 AS antisense and hSMP mut TRE1 SS/ hSMP PCR1R1 antisense; for TRE2: hSMP mut TRE2 sense/ hSMP PCR2Rlantisense and hSMP PCR2F1 sense/hSMP mut TRE2 antisense; The PGR amplification for mut TRE1was performed using step cycles $\left(94^{\circ} \mathrm{C}\right.$ for $30 \mathrm{~s}$, $65^{\circ} \mathrm{C}$ for $30 \mathrm{~s}, 74^{\circ} \mathrm{C} 30 \mathrm{~s}$ ) for 35 cycles with a final extension at $74^{\circ} \mathrm{C}$ for 10 minutes. The PCR amplification for mut TRE2 was performed using step cycles $\left(94^{\circ} \mathrm{C}\right.$ for $30 \mathrm{~s}, 60^{\circ} \mathrm{C}$ for $30 \mathrm{~s}, 72^{\circ} \mathrm{C}$ $30 \mathrm{~s}$ ) for 35 cycles with a final extension at $72^{\circ} \mathrm{C}$ for 10 minutes. Both the PCR products were purified using QIAquick Gel Extraction Kit. DNA was eluted using $30 \mu \mathrm{l}$ of autoclaved deionised water. $30 \mathrm{ng}$ of each PCR product was used as a template for the second round of PCR. For example: for construction of mutant TRE1site: $30 \mathrm{ng}$ each of the PCR product hSMP PCR1F2/ hSMP mut TRE1 AS antisense and hSMP mut TRE1 SS/ hSMP PGR1R1 antisense. Similarly mutant TRE2 was made. PCR amplification was carried out using the same parameters as mentioned above. Then the PCR products were purified using QIAquick Gel Extraction Kit. The fragments with mutated TRE sites, having KpnI and XhoI restriction sites and pGL3-Basic vector were digested with $\mathrm{KpnI}$ and XhoI enzyme. The fragments were then ligated into restriction enzyme digested pGL3-Basic vector using DNA ligase. The cloned fragments were then confirmed by vector specific PCR using RV3 and GL2 primer, and the mutation was confirmed by sequencing.

Table 6. Primers Used for site directed mutagenesis.

\begin{tabular}{ll}
\hline & \\
\hline & Sequence $\mathbf{5}^{\prime} \mathbf{- 3}^{\prime}$ \\
\hline hSMP PCR 1F2 & CACCACGCCCGGCTAATTTG \\
hSMP30 mutTRE1 SS & ATGTTAGTAAGGCTGGTCTCAAACTCCTGAAATTAGG \\
hSMP30 mutTRE1 AS & CCTAATTTCAGGAGTTGAGACCAGCCTTACTACAT \\
hSMP PCR 1R1 & GGCAACAAAGTGAGACTTCGTCTC \\
hSMP PCR 2F & GGCAGTGCCAACATAGAAGG \\
hSMP30 mutTRE2 SS & GAAAGAAATTAAAGGGACAATTCTATGAAATGGTG \\
hSMP30 mutTRE2 AS & CACCATTTCATAGAATTGTCCCTTTAATTCTTC \\
hSMP PCR 2R1 & CTTCCTCAGTGCTGATGTCTCCC \\
\hline doi:10.1371/journal.pone.0020861.t006
\end{tabular}




\section{Supporting Information}

Figure S1 Determination of hSMP30 Transcription start site (TSS). Determination of transcription initiation sites by primer extension analysis. A Lane 1-4, sequencing reactions; lane 5 , primer extension product of MCF-7 total RNA, lane 6, labeled DNA marker from Promega. The sequence corresponding to the transcription start site has been marked by a line and is complementary to the sequencing reactions shown in the figure. B. A schematic diagram of human SMP30 promoter showing two TREs, CAAT box and transcription start site.

(DOG)

Figure S2 To analyze the effect of T3 on SMP30 Promoter activity in MCF-7 cell in relation to $R X R \alpha$. Transient transfections of hSMP30 TRE1, TRE2 were carried out using MCF-7 cells. $20 \mathrm{hrs}$ before transfection, cells were plated in DMEM $10 \%$ CS media, at a density of $1 \times 10^{5}$ cells per well in 12 well plates. For transient transfection, $0.5 \mu \mathrm{g}$ of reporter plasmid DNA, $0.5 \mu \mathrm{g}$ of $\mathrm{TR} \beta$ and TR $\alpha$ (TRs), RXRA $\alpha$ expression vector, $100 \mathrm{ng}$ of ${ }_{\mathrm{p}} \mathrm{RL}$-TK control vector and only vector to control cells were co transfected using Fugene HD transfection reagent (from Roche) as per manufacture's instruction. After $24 \mathrm{hrs}$ of transfection, cells were subjected to overnight treatment with $1 \mu \mathrm{M}$ T3 and vehicle to control cells in 10\% CS -DMEM. Then cell lysates were prepared and luciferase activities were measured. Values are the mean of three independent experiments \pm SD normalized to Renilla activity. $* * * \quad P<0.0001$ difference from vehicle control using ANOVA.

(DOC)

Figure S3 Luciferase activity of SMP30 TREs in HEK293 cell line. Transient transfections of hSMP30 TRE1, TRE2 were

\section{References}

1. Porter P (2008) "Westernizing "women's risks? Breast cancer in lower income countries," NEJM 358;3): 213-216.

2. The Lancet, "Breast cancer in developing countries," The Lancet, 374(9701): 1567-2131.

3. Tfayli A, Temraz S, Mrad RA, Shamseddine A (2010) Breast cancer in low and middle income countries: an emerging and challenging epidemic. Journal of Oncology 2010: 1-5.

4. Kim JJ, Champan-Davis E (2010) Role of progesterone in endometrial cancer. Semin Rerod Med 28: 81-90.

5. Lewis-Wambi JS, Jordan VC (2009) Estrogen regulation of apoptosis: how can one hormone stimulate and inhibit? Breast Cancer Res 11: 206.

6. Mazumdar A, Wang RA, Mishra SK, Adam L, Bagheri-Yarmand R, et al. (2001) Transcriptional repression of oestrogen receptor by metastasis-associated protein 1 corepressor. Nat Cell Biol 3(1): 30-7.

7. Mishra SK, Yang Z, Mazumdar A, Talukder AH, Larose L, et al. (2004) Metastatic tumor antigen 1 short form (MTA1s) associates with casein kinase Igamma2, an estrogen-responsive kinase. Oncogene 23(25): 4422-9.

8. Ahmad N, Kumar R (2011) Steroid hormone receptors in cancer development: a target for cancer therapeutics. Cancer Lett 300: 1-9.

9. Nicholson RI, Johnston SR (2005) Endocine therapy current benifits and limitations. Breast Cancer Res Treat 93: S3-S10.

10. Denis LJ, Griffiths K (2000) Endocrine treatment in prostate cancer. Semin Surg Oncol 18: 52-74.

11. Silva JM, Dominguez G, Gonzalez-Sanccho JM, Garcia JM, Silva J, et al. (2002) Expression of thyroid hormone receptor/erbA genes is altered in human breast cancer. Oncogene 21: 4307-4316.

12. Martinez MB, Ruan M, LA Fizpatrick LA (2000) Altered response to thyroid hormones by prostrate and breast cancer cells. Cancer Chemother Pharmacol 2000: 45: 93-102.

13. Turken O, Narin Y, Demirbas S, Onde ME, Sayan O, et al. (2003) Breast cancer in association with thyroid disorders. Breast Cancer Res 5: 110-113.

14. Mangelsdorf D, Thummel C, Beato M, Herrlich P, Schutz G, et al. (1995) The nuclear receptor superfamily: the second decade. Cell 83: 835-839.

15. Vonderhaar BK, Greco A (1979) Lobulo-alveolar development of mouse mammary glands is regulated by thyroid hormones. Endocrinol 104: 409-418.

16. Lopez-Barahona M, Fialka I, Gonzalez-Sancho JM, Asunción M, González M, et al. (1995) Thyroid hormone regulates stromelysin, protease secretion and the morphogenetic potential of normal polarized mammary epithelial cells. EMBOJ 14: 1145-1155. carried out using HEK 293 cells. 20 hrs before transfection, cells were plated in DMEM 10\% CS media, at a density of $1 \times 10^{5}$ cells per well in 12 well plates. For transient transfection, $0.5 \mu \mathrm{g}$ of reporter plasmid DNA, $0.5 \mu \mathrm{g}$ of $\mathrm{TR} \beta$ and $\mathrm{TR} \alpha(\mathrm{TRs}), \mathrm{RXR} \alpha$ expression vector, $100 \mathrm{ng}$ of ${ }_{\mathrm{p}} \mathrm{RL}-\mathrm{TK}$ control vector and only vector to control cells were co transfected using Fugene HD transfection reagent (from Roche) as per manufacture's instruction. After 24 hrs of transfection, cells were subjected to overnight treatment with $1 \mu \mathrm{M}$ T3 and vehicle to control cells in $10 \% \mathrm{CS}-$ DMEM. Then cell lysates were prepared and luciferase activities were measured. Values are the mean of three independent experiments $\pm \mathrm{SD}$ normalized to Renilla activity. $* * * P<0.0001$ difference from vehicle control using ANOVA.

(DOC)

\section{Acknowledgments}

We thank Dr. Ronald M. Evans, The Salk Institute for Biological Studies, San Diego, CA. for providing us ${ }_{p}$ CMX-hRXR- $\alpha$ p GMX-hTR $\beta$ and p CMX-rTR $\alpha$ plasmid constructs. We also acknowledge the contribution of Mr. Dharmendra Bhargava in helping us out for presentation of part of this work in the Symposia on Gancer Research 2010: Personalized Cancer Therapy and Prevention, October 8-9, 2010 in UT MD Anderson Cancer Center, Houston, TX, USA.

\section{Author Contributions}

Conceived and designed the experiments: PS SKM. Performed the experiments: PS. Analyzed the data: PS. Contributed reagents/materials/ analysis tools: PS ADM. Wrote the paper: PS SKM. Participated in cloning of promoter deletion constructs: RP. Participated in PCR related experiments: BR. Participated in experiments related to FACS: ADM. Project hypothesis, guidance, critical revision of the manuscript: SKM.

17. Gonzalez-Sancho JM, Figueroa A, Lopez-Barahona M, López E, Beug H, et al. (2002) Inhibition of proliferation and expression of Tland Cyclin D1genes by thyroid hormone in mammary epithelial cells. Mol Carcinog 34: 25-34.

18. Smyth PPA (1997) The thyroid and breast cancer: a significant association. Ann Med 29: 189-191.

19. Yokoe T, lino Y, Takei H, Horiguchi J, Koibuchi Y, et al. (1996) Relationship between thyroid-pitutary function and response and response to therapy in patients with recurrent breast cancer. Anticancer Res 16: 2069-2072.

20. Yokoe T, lino Y, Takei H, Horiguchi J, Koibuchi Y, et al. (1997) Changes of cytokines and thyroid function in patients with recurrent breast cancer. Anticancer Res 17: 695-699.

21. Conde I, Paniagua R, Zamora J, Blanquez MJ, Fraile B, et al. (2006) Influence of thyroid hormone receptors on breast cancer cell proliferation. Annals of Oncology 17: 60-64.

22. Cestari SH, Figueiredo NB, Conde SJ, Clara S, Katayama MLH, et al. (2009) Influence of estradiol and triiodothyronine on breast cancer cell lines proliferation and expression of estrogen and thyroid hormone receptors. Arq Bras Endocrinol Metab 53(7): 859-64.

23. Guigon CJ, Kim DW, Willingham MC, Cheng S-y (2011) Mutation of the thyroid hormone receptor- $\beta$ in mice predisposes to the development of mammary tumors. Oncogene 1-10.

24. Smallridge RC, Latham KR (1980) Nuclear thyroid hormone receptor in human breast tumors. Clinical Res 28: 421.

25. Alvardo-Pisani AR, Chacon RS, Betancourt LJ, López-Herrera L (1986) Thyroid hormone receptors in human breast cancer: effect of thyroxine administration. Anticancer Res 6: 1347-1351.

26. Burke RE, McGuire WL (1978) Nuclear thyroid hormone receptors in a human breast cancer cell line. 38: 3769-3773.

27. Zhou-Li F, Albaladejo V, Joly-Pharaboz MO, Nicolas B, Andre J (1992) Antiestrogens prevent the stimulatory effects of L-triiodothyronine on cell proliferation. Endocrinol 130: 1145-1152.

28. Yen PM, Ando S, Feng X, Maruvada P, Xia X (2006) Thyroid hormone action at the cellular, genomic and target gene levels. Mol Cell Endocrinol 246: $121-127$.

29. Lazar MA (2003) Thyroid hormone action: a binding contract. J Clin Investig 112: 497-499.

30. Tagami T, Madison LD, Nagaya T, Jameson JL (1997) Nuclear receptor corepressors activate rather than suppress basal transcription of genes that are negatively regulated by thyroid hormone. Mol Cell Biol 17: 2642-2648. 
31. Tagami T, Park Y, Jameson JL (1999) Mechanisms that mediate negative regulation of the thyroid stimulating hormone alpha gene by thyroid hormone receptor. J Biol Chem 274: 22345-22353.

32. Sasaki S, Lesson-Wood L A, Dey A, Kuwata T, Weintraub BD, et al. (1999) Ligand induced recruitment of a histone deacetylase in the negative feedback regulation of the thyrotropin $\beta$ gene. EMBO J 18: 5389-5398.

33. Yen PM, Feng X, Flamant F, Chen Y, Walker RL, et al. (2003) Effects of ligand and thyroid hormone receptor isoforms on hepatic gene expression profiles of thyroid hormone receptor knockout mice. EMBO Rep 4: 581-587.

34. Narayanan CH, Narayanan Y, Browne RC (1986) Development of the spinal tract of the trigeminal nerve and its relation to early fetal behaviour in rats under normal and hypothyroid conditions. Exp Brain Res 62: 61-76.

35. Mihara S, Suzuki N, Wakisaka S, Suzuki N, Wakisaka S, et al. (1999) Effects of thyroid hormones on apoptotic cell death of human lymphpocytes. J Clin Endocrinol Metab 84: 1378-1385.

36. Hara M, Suzuki S, Mori J, Yamashita K, Kumagai M, et al. (2000) Thyroid hormone regulation of apoptosis induced by retinoic acid in promyeloleukemic HL-60 cells studies with retinoic acid receptor-specific and retinoid X-receptor specific ligands. Thyroid 10: 1023-1034.

37. Fujita T, Uchida K, Maruyama N (1992) Purification of Senescence marker protein-30 (SMP30) and its androgen independent decrease with age in the rat liver. Biochim Biophys Acta 1116: 122-128.

38. Fujita T, Inoue H, Kitamura T, Sato N, Shimosawa T, et al. (1998) Senescence marker protein-30 (SMP30) rescues cell death by enhancing plasma membrane $\mathrm{Ca}^{2+}$ pumping activity in HepG2 cells. Biochem Biophys Res Commun 250: $374-380$.

39. Ishigami A, Fujita T, Handa S, Shirasawa T, Koseki H, et al. (2002) Senescence marker protein-30 knockout mouse liver is highly susceptible to tumor necrosis factor alpha- and Fas- mediated apoptosis. Am J Pathol 161: 1273-1281.

40. Jeong DH, Goo M J, Hong IH, Yang HJ, Ki MR, et al. (2008) Inhibition of radiation induced apoptosis via overexpression of SMP30 in Smad3- knockout mice liver. J Radiat Res 49: 653-660.

41. Handa S, Maruyama N, Ishigami A (2009) Overexpression of Senescence marker protein-30 decreases reactive oxygenspecies in human hepatic carcinoma HepG2 cells. Biol Pharm Bull 32(10): 1645-1648.

42. Sar P, Rath B, Subudhi U, Chainy GBN, Supakar PC (2007) Alterations in expression of Senescence marker protein-30 (SMP30) gene by3,3' 5 triiodo Lthyronine $\left(\mathrm{T}_{3}\right)$. Mol Cell Biochem 303: 239-242.

43. Williams GR, Brent GA Basic concepts and clinical correlations Mol Endocrinol (Weintraub, B. D., ed). pp 217-239.

44. Katz RW, Koenig RJ (1993) Nonbiased identification of DNA sequences that bind TH receptor alpha 1 with high affinity. J. Biol. Chem 268: 19392-19397.

45. Wang D, Xia X, Liu Y, Oetting A, Walker RL, et al. (2009) Negative regulation of $\operatorname{TSH} \alpha$ target gene by thyroid hormone involves histone acetylation and corepressor complex dissociation. Mol Endocrinol 23: 600-609.

46. Santos GM, Afonso V, Barra GB, Togashi M, Webb P, et al. (2006) Negative regulation of Superoxidedismutase-1 promoter by thyroid hormone. Mol Pharma 70(3): 793-800.

47. Nygard M, Becker N, Demenix B, Pettersson K, Bondesson M (2006) Thyroid hormone mediated negative transcriptional regulation of Necdin expression. J Mol Endocrinol 36: 517-530.

48. Kim SW, Ho SC, Hong S J, Kim KM, So EC, et al. (2005) A novel mechanism of thyroid hormone dependent negative regulation by thyroid hormone receptor, nuclear receptor corepressor (NCoR), and GAGA-binding factor on the rat CD44 promoter. J Biol Chem 280(15): 14545-14555.

49. Shibusawa N, Hashimoto K, Nikrodhanond AA, Liberman MC, Applebury ML, et al. (2003) Thyroid hormone action in the absence of thyroid hormone receptor DNA-binding in vivo. J Clin Invest 112: 588-597.

50. Saatcioglu F, Deng T, Karin M (1993) A novel cis element mediating ligandindependent activation by c-ErbA: Implications for hormonal regulation. Cell 75: 1095-1105.
51. Berghagen H, Ragnhildstveit E, Krogsrud K, Thuestad G, Apriletti J, et al. (2002) Corepressor SMRT functions as a coactivator for thyroid hormone receptor $\mathrm{T} 3 \mathrm{R} \alpha$ from a negative hormone response element. J Biol Chem 277: 49517-49522.

52. Ishi S, Yamada M, Satoh T, Monden T, Hashimoto K, et al. (2004) Aberrant dynamics of histone deacetylation at the thyrotropin releasing hormone gene in resistance to thyroid hormone. Mol Endocrinol 18: 1708-1720.

53. Shibusawa N, Hollenberg AN, Wondisford FE (2003) Thyroid hormone receptor DNA binding is recquired for both positive and negative gene regulation. J Bio Chem 278: 732-738.

54. Wang D, Xia X, Weiss R, Refetoff S, Yen PM (2010) Distinct and histone specific modifications mediate positive verus negative transcriptional regulation of TSH $\alpha$ promoter. PLoSONE 5(3): 1-12.

55. Chimenti D, Bizzarri B, Maccioni E, Secci D, Bolasco A, et al. (2009) A novel histone acetyltransferase inhibitor modulating GCN5 network: cyclopentylidiene-[4-(4'- chlorophenyl) thiazol-2-yl)hydrazone. J Med Chem 52: 530-536.

56. Elsheikh SE, Green AR, Rakha EA, Powe DG, Ahmed RA, et al. (2009) Global histone modifications in breast cancer correlate with tumor phenotypes, prognostic factors, and patient outcome. Cancer Res 69(9): 3802-9.

57. Diaz-Cruz ES, Furth PA (2010) Deregulated estrogen receptor $\alpha$ and p53 heterozygosity collaborate in the development of mammary hyperplasia. Cancer Res 70(10): 3965-74.

58. Alonso M, Goodwin C, Liao X, Ortiga-Carvalho T, Machado DS, et al. (2009) In vivo interaction of steroid receptor coactivator (SRC)-1 and the activation function-2 domain of the thyroid hormone receptor (TR) beta in TRbeta E457A knock-in and SRC-1 knockout mice. Endocrinol 150(8): 3927-3934.

59. Ortiga-Carvalho TM, Shibusawa N, Nikrodhamond A, Olivera KJ, Machado DS, et al. (2005) Negative regulation by thyroid hormone receptor requires an intact coactivator binding surface. J Clin Invest 115: 2517-2523.

60. Tagami T, Gu W-X, Peairs PT, West B, Jameson JL (1998) A novel natural mutation in the thyroid hormone receptor defines a dual functional domain that exchanges nuclear receptor corepressor and coactivators. Mol Endocrinol 12: 1888-1902.

61. Mishra SK, Mazumdar A, Vadlamudi RK, Li F, Wang RA, et al. (2003) MICoA, a novel metastasis-associated protein 1 (MTA1) interacting protein coactivator, regulates estrogen receptor- $\alpha$ transactivation functions. J Biol Chem 278: 19209-19219.

62. Glozak MA, Seto E (2007) Histone deacetylases and cancer. Oncogene 26: $5420-32$.

63. Duan H, Heckman CA, Boxer LM (2005) Histone deacetylase inhibitors downregulate bcl-2 expression and induce apoptosis in t $(14 ; 18)$ lymphomas. Mol Cell Biol 25: 1608-1619.

64. Wilson MA, Ricci AR, Deroo BJ, Archer TK (2002) The histone deacetylase inhibitor trichostatin A blocks progesterone receptor mediated transactivation of the mouse mammary tumor virus promoter in vivo. J Biol Chem 277: $15171-15181$

65. Chou C-W, Wu M-S, Huang W-C, Chen C-C (2011) HDAC inhibition decreases the expression of EGFR in colorectal cancer cells. PLoSONE 6(3): $1-2$.

66. Rath B, Pandey RS, Debata PR, Maruyama N, Supakar PC (2008) Molecular characterization of senescence marker protein-30 gene promoter: identification of repressor elements and functional nuclear factor binding sites. BMC Mol Biol 9: 43: $1-15$.

67. Liu Y, Xia X, Fondell JD, Yen PM (2006) Thyroid hormone-regulated target genes have distinct patterns of coactivator recruitment and histone acetylation. Mol Endocrinol 20: 483-490.

68. Park SW, Li G, Lin YP, Barrero MJ, Cre K (2005) Thyroid hormone induced juxtaposition of regulatory elements/factors and chromatin remodelling of Crabpl dependent on MED1/TRAP220. Mol Cell 19: 643-653. 